\title{
DAS FORTWIRKEN DER LEGENDE VON BARLAAM UND IOASAPH IN DER BYZANTINISCHEN HAGIOGRAPHIE, INSBESONDERE IN DEN WERKEN DES SYMEON METAPHRASTES*
}

Quel public vise ainsi le rédacteur de Barlaam et Ioasaph? Un moine ici écrit pour des moines. Et les nombreux exemplaires du roman au Mont Athos, à Saint-Sabas, au Sinaï, par exemple, attestent sa popularité en ce milieu. Mais l' horizon de réception a été sans doute plus étendu, jusqu'en un public laïc. ${ }^{1}$

In der Tat ist der Wirkungskreis der Barlaam-Legende bereits in Byzanz enorm: So zitiert sie Michael Glykas (12. Jh.) - sie ausdrücklich nennend - mehrfach als theologische Autorität, einmal in seiner Weltchronik und sieben Mal in seiner exegetischen Briefsammlung ${ }^{2}$. Andere Autoren schöpfen ohne jeden Hinweis aus dem großen geistlichen Roman: Um die

* Ein kurzer Auszug aus dieser Studie wurde vom Verfasser am 22. August 2001 auf dem 20. Internationalen Byzantinistenkongreß zu Paris vorgetragen; vgl. a. das Résumé in $\mathrm{XX}^{\mathrm{e}}$ Congrès International des Études Byzantines, Collège de France - Sorbonne, 19-25 août 2001. Pré-actes, 3: Communications libres. Paris 2001, 120. Herrn Professor Wolfram Hörandner möchte ich auch an dieser Stelle für seine Bereitschaft, die ungekürzte Fassung im $J O ̈ B$ zu veröffentlichen, ganz herzlich danken.

${ }^{1}$ M. Alexandre, Barlaam et Ioasaph. La conversion du héros et du roman, in: Le monde du roman grec. Actes du colloque international tenu à l'École normale supérieure (Paris 17-19 décembre 1987) rassemblés par M.-F. Baslez, Ph. Hoffmann et M. Trédé. Paris 1992, 259-282, hier 261.

${ }^{2} \mathrm{Vgl}$. Michaelis Glycae annales, recognovit I. BеккеR. Bonn 1836, 167,15-17 entsprechend Barlaam-Kapitel 7 ( $P G$ 96, 905,35-37 bzw. in der nach Kapiteln und Zeilen

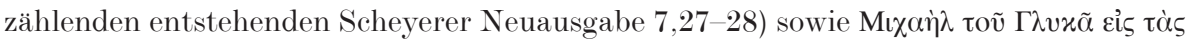

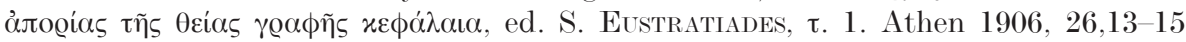
entsprechend wiederum Barlaam-Kapitel 7 ( $P G$ 96, 905,35-37 bzw. demnächst 7,27-28); 32,11-12 entsprechend nochmals Barlaam-Kapitel 7 (PG 96, 905,35-37 bzw. demnächst 7,27-28); 130,7-12 entsprechend Barlaam-Kapitel 8 ( $P G$ 96, 921,13-20 bzw. demnächst 8,71-76); 419,17-20 entsprechend Barlaam-Kapitel 12 ( $P G$ 96, 976,51-54 bzw. demnächst 12,267-269) und ebd. $\tau$. 2. Alexandria 1912, 217,2-8 entsprechend BarlaamKapitel 9 ( $P G$ 96, 933,40-46 bzw. demnächst 9,108-113); 226,21-227,2 entsprechend Barlaam-Kapitel 8 ( $P G$ 96, 928,8-16 bzw. demnächst 8,161-167; 343,21-23 entsprechend Barlaam-Kapitel 12 (PG 96, 965,20-23 bzw. demnächst 12, 72-74). 
Parabel von den vier Kästchen aus dem 6. Kapitel rankt sich das erst seit wenigen Jahren bekannte volkssprachliche Versepos vom Sebastokrator Thomas aus dem 13./14. Jahrhundert ${ }^{3}$. Manuel Philes (ebenfalls 13./14. Jh.) verarbeitet die auch unter den Bezeichnungen Mann im Brunnen oder Von der Süße der Welt bekannte Einhornparabel des 12. Kapitels in sechs Gedichten, wobei ihn eventuell eine bildliche Darstellung derselben anregte ${ }^{4}$.

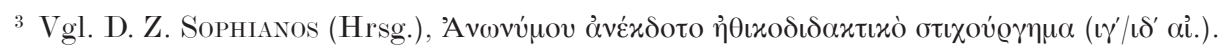

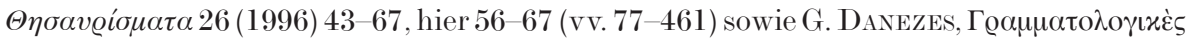

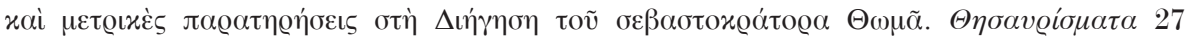
(1997) 27-35, hier 27-31.

${ }^{4}$ Vgl. Manuelis Philae carmina ex codicibus Escurialensibus, Florentinis, Parisinis et Vaticanis nunc primum edidit E. Miller, 1. Paris 1855, 126-129 (= carm. 246 und

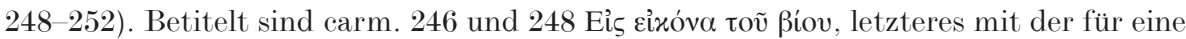

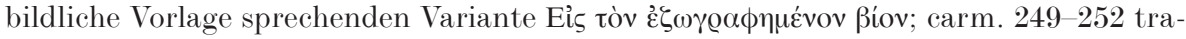
gen den schlichten Titel Eis tò av̉ió. Zwingend anzunehmen ist jedoch die Vorlage einer Illustration keineswegs, die ganze Parabel zeichnet ja ein Bild des Lebens, und mit dem Titel Ein Bild des menschlichen Lebens ist z. B. ihre Nachdichtung durch den süddeutschen Geistlichen, Pädagogen und Jugendschriftsteller Christoph v. Schmid (1768-1854) überschrieben; sie bildet eine Zugabe zu seiner erstmals 1839 erschienenen Erzählung Josaphat - Königssohn von Indien, vgl. Chr. v. Schмid, Drei Parabeln Barlaams, in: Ders., Gesammelte Schriften. Originalausgabe von letzter Hand, 15. Augsburg 1843, 187-194, hier 191-192, wo allerdings die Hoffnungslosigkeit durch die Einführung eines die Szenerie beobachtenden Engels - Personifikation der Religion - gemildert ist; er steht bei Schmid bereit, um einen auf den Honiggenuß verzichtenden, bis zum Ende ausharrenden Menschen aufzufangen und zu retten, während sich ein nach dem Honig streckender abstürzt und ein Raub des Drachens wird. Noch heute existieren illustrierte Handschriften und Drucke vom Buch der Beispiele der alten Weisen des Antonius von Pforr $(\dagger 1483)$, welcher die von Johannes v. Capua (1263-1278) ins Lateinische übertragene, um 1250 entstandene hebräische Fassung des Kalīla wa-Dimna ins Deutsche übersetzte. Ein solches Exemplar diente wohl Hans Sachs (1494-1576) für sein Poem Ein Figur des Menschen elenden, geferlichen Lebens, wenn er diese Szenerie als gebildet und gemalt bezeichnet und dennoch vieles aus seiner genannten Textvorlage wörtlich übernimmt; vgl. Hans Sachs, hrsg. von A. v. Keller, 4. Stuttgart 1870, 82-84 und Das Buch der Beispiele der alten Weisen, nach Handschriften und Drucken hrsg. von W. L. Holland. Stuttgart 1860, 20,11-33. Hier sind wir allerdings schon beim zweiten großen Überlieferungsstrang dieser ursprünglich aus dem indischen Epos Mahābhārata (XI,5) stammenden Parabel angelangt, nämlich dem sie enthaltenden, wohl auf den persischen Arzt Borzōe (6. Jh.) zurückgehenden dritten Prolegomenon des arabischen Kalīla wa-Dimna.

Wie schon angedeutet ist dieses Motiv in der darstellenden Kunst verbreitet, der früheste byzantinische Zeuge aus der Buchmalerei - von illuminierten Handschriften der Barlaam-Legende einmal abgesehen - dürfte der Londoner Psalter (cod. Lond. Brit. Libr. Addit. 19.352) von 1066 sein, der es, mit ausführlichen Bildlegenden versehen, auf

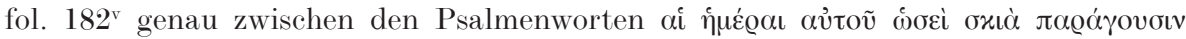

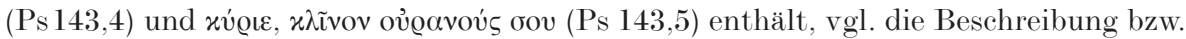
Reproduktion bei S. Der Nersessian, L'illustration des psautiers grecs du Moyen Âge, 
Der kretische Dichter Mpergades (15. Jh.) spinnt in seinem Apokopos das Motiv zu einer Traumvision um und betrachtet sich selbst als der vom

2. Paris 1970, 57 bzw. pl. 101, fig. 286. Der Barberini-Psalter (cod. Vat. Barb. gr. 372) aus dem 11./12. Jh. enthält auf fol. $231^{\vee}$ an derselben Psalmenstelle eine praktisch identische Illustration mit wesentlich kürzeren Bildlegenden, vgl. Der Nersessian, op. cit. 69 m. Anm. 3 bzw. pl. 118, fig. 332 .

Ins 10. Jh. zu datieren und damit älter ist ein im Louvre (Inventar-Nr. X 4903) aufbewahrtes Stückchen koptischen Stoffs, auf das uns A. Kakovkin, Une étoffe copte avec l'image au sujet d'une parabole du livre de Barlaam et Josaphat. Göttinger Miszellen 134 (1993) 55-61 (mit Zeichnung des Musters) und Ders., Koptskaja tkan's izobraženiem pritči iz „Povesti o Varlaame i Ioasafe“. VV 59 (84) (2000) 222-225 (mit Foto) hinweist: Es ist $12 \times 7 \mathrm{~cm}$ groß und weist ein blattförmiges Muster auf, das stark stilisiert einen Menschen darstellt, der mit erhobenen Armen sich auf der Krone einer tragfähigen belaubten Pflanze befindet, deren dünner Stamm offenbar gerade von zwei Mäusen oder Ratten durchgenagt worden ist. Erstmals beschrieben (une plante surmontée d'un personnage bras levés et à laquelle sont affrontés deux bouquetins) und reproduziert wurde dieses Bildnis bei P. Du Bourguet, Musée National du Louvre. Catalogue des étoffes coptes, 1. Paris 1964, 359, Abb. G 44; die auf den Stamm der Pflanze - und dieser Stamm ist eindeutig unterbrochen, durchgenagt, was Kakovkin seltsamerweise gar nicht eigens hervorhebt - blickenden Tiere mit ihren spitzen Schnauzen, großen Ohren, langen dünnen Schwänzen und charakteristischen Pfötchen haben für Kakovkin wie auch für den unbedarften Betrachter allerdings keine Ähnlichkeit mit Steinböcken (bouquetins), sondern gemahnen eindeutig an mausartige Nagetiere. In der koptischen Textilproduktion stieß Kakovkin auf insgesamt noch vier vergleichbare, aber alles andere als identische Stücke. Das älteste stammt eventuell aus dem 6. Jh. und wurde 1948 vom Textile Museum zu Washington, D.C. erworben (Inventar-Nr. 72.126); es wird als Dekorationsmuster einer Tunika definiert, ist ähnlich blattförmig und zeigt einen Menschen, am ehesten eine Frau, mit erhobenem linken Arm auf einem Baum, der eventuell ein Weinstock sein könnte; flankiert wird dieser Baum, dessen Stamm selbstverständlich intakt ist, von zwei animals - genauer kann sie auch der Katalog nicht deuten -, die senkrecht zum Baum stehen und in zwei verschiedene Richtungen, nämlich zum Himmel und zum Boden, blicken, vgl. die Reproduktion und in erster Linie textiltechnische Beschreibung bei J. Trilling, The Roman heritage. Textiles from Egypt and the Eastern Mediterranean 300 to 600 A. D. Washington, D. C. 1982, 55, Abb. 38. Aus dem 7.-8. Jh. stammt ein ebenfalls blattförmiges Stück in einer österreichischen Privatsammlung, das überdeutlich einen nackten Mann mit erhobenen Armen in Frontalansicht in der Krone eines Baumes mit intaktem Stamm zeigt, der von zwei am ehesten wie Hasen aussehenden Tieren flankiert wird, die senkrecht zum Baum in einer in der Natur gar nicht möglichen Stellung mit vier erhobenen Läufen auf ihrem Hinterteil hocken und beide in die gleiche Richtung, nämlich himmelwärts, blicken; interpretiert wird dies als Szene aus dem dionysischen Themenkreis - ein Erot im zum Baum ausgebildeten Weinstock, umgeben von Tieren, vgl. die Reproduktion und Beschreibung bei P. Bichler, Antike koptische Textilien aus österreichischem Privatbesitz. Schallaburg 1989, 29-30 (Katalog-Nr. 16). Weniger fein gearbeitet sind die Muster zweier vergleichbarer rechteckiger Stücke: Das ältere existiert in zweifacher Ausfertigung, stammt aus dem 6.-7. Jh. und war Bestandteil einer 1961 in der Krefelder Gewebesammlung ausgestellten Privatsammlung; dargestellt ist eine mit erhobenen 
Drachen verschlungene Mann, der auf diese Weise seine Hadesfahrt antritt $^{5}$. Und es sieht so aus, als ob sogar Historiker wie Johannes Skylitzes

Armen über einer Baumkrone stehende oder tanzende menschliche Figur, der Baum ist von zwei Tieren - Antilopen oder Hasen - flankiert, die wie auf dem gerade genannten österreichischen Stück senkrecht zum Baum in völlig unnatürlicher Haltung mit erhobenen Vorderläufen auf ihrem Hinterteil hocken und himmelwärts blicken, vgl. Textilkunst des frühen Christentums. Koptische Gewebe vom 2.-12. Jh. Krefeld 1961, Nr. 126 und Taf. 8. Stark ähnelt diesem Stück schließlich das noch etwas gröber gearbeitete Muster im Hildesheimer Pelizaeus-Museum (Inventar-Nr. 3073) aus dem 9./10. Jh., vgl. E. EgGebrecht, Spätantike und koptische Textilien, 1. Mainz 1978, 2,9-2,11. Das Stück aus dem Louvre ist somit das jüngste der behandelten Muster und kopiert keines von ihnen; mit KaKovkin, op. cit., $224 \mathrm{zu}$ sprechen, sind die bei ihm dargestellten Tiere ziemlich sicher bestimmbar (Mäuse) und die ganze Szene ist interpretierbar, während bei den anderen Stücken klar das dekorative Element vorherrscht. Seines Wissens ist dieses bescheidene, in technischer und künstlerischer Hinsicht völlig mittelmäßige Denkmal die einzige Darstellung einer Episode des Barlaam-Romans auf einem Textilstück. Das Mustermotiv eines Menschen im Baum, flankiert von zwei Tieren, gab es in der koptischen Textilkunst seit Generationen; hier brauchte das Motiv nur durch die Barlaam-Parabel variiert werden. Besonders schön gearbeitete Darstellungen aus dem 4.-5. Jh. von Dionysos im zum Baum ausgebildeten, aus einer großen Amphore wachsenden Weinstock, flankiert von zwei auf diesen Weinstock blickenden, seine Zweige benagenden Hirschen bzw. Antilopen, finden sich in der Petersburger Eremitage (Inventar-Nr. 11153-11154), vgl. M. Mat'e i K. Ljapunova, Chudožestvennye tkani koptskogo Egipta. Moskau, Leningrad 1951, 109-110 (Nr. 75-76) und tabl. XXVI. Dem mehrfach dokumentierten Hinweis Kakovkins, daß es sich oft um eine Frau in den Zweigen eines Gewächses handle, was als Darstellung der altägyptischen Göttin Nut interpretiert werde, könnte vielleicht die Darstellung der hl. Thekla auf einem relativ bekannten koptischen Steinrelief im New Yorker Brooklyn-Museum (InventarNr. 40.299, vage vom 6 . bis ins 9 . Jh. datiert) ergänzend zugefügt werden; die Heilige befindet sich mit erhobenen Armen zwischen üppigem Gebüsch in der Bildmitte und wird von beiden Seiten von je einem großen Hund oder Wolf angesprungen, vgl. C. Nauerth - R. Warns, Thekla. Ihre Bilder in der frühchristlichen Kunst. Wiesbaden 1981, 63-69 und Abb. 23.

$\mathrm{Zu}$ drei westlichen Reliefdarstellungen der Einhornparabel (befindlich in Ferrara, Parma und Joigny) vgl. R. Jultian, Un nouveau monument sculpté de la légende de Saint Barlaam. Mélanges d'archéologie et d'histoire 48 (1931) 170-184 und generell, mit Schwerpunkt Parma, A. SicLari, L'apologo del „Barlaam e Joasaph“ e la letteratura agiografica degli „exempla“, in: Il Battistero di Parma. Iconografia, iconologia, fonti letterarie. A cura di G. Schianchi. Mailand 1999, 351-373. Eine wahre Fundgrube zu Darstellungen der Parabel in postbyzantinischen Wandmalereien auf heute griechischem Gebiet

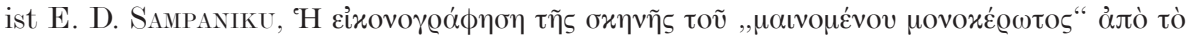

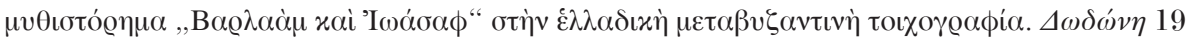
(1990), Nr. 1, 127-157.

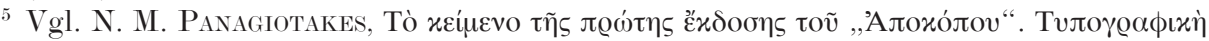

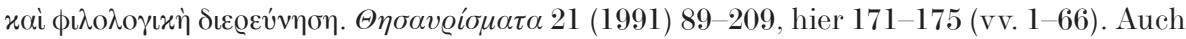
in diesem Fall wird die Vorlage einer bildlichen Darstellung diskutiert, vgl. C. LucianI, Elementi iconografici nella struttura dell'Apokopos, in: Origini della letteratura neogreca. 
(11./12. Jh.), Georgios Pachymeres (13. Jh.) und Nikephoros Gregoras (14.Jh.) gelegentlich griffige sprachliche Elemente aus dem Barlaam-Roman übernehmen ${ }^{6}$.

I.

Die Geheimrat Franz Bücheler (1837-1908) ${ }^{7}$ zur Feier seines 25jährigen Wirkens in Bonn 1895 gewidmete Studie von Paul Rabbow (1867-1956) über die Legende des Martinian ${ }^{9}$ ist in vielerlei Hinsicht bemerkenswert.

Atti del secondo congresso internazionale „Neograeca Medii Aevi“ (Venezia, 7-10 novembre 1991) a cura di Nicolaos M. Panayotakis, 2. Venedig 1993, 191-204, hier 200201.

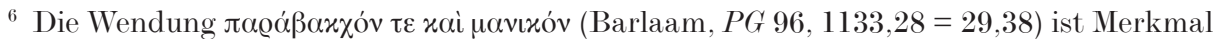
der urtextnahen Gruppe und der Modifikation A; in den anderen Modifikationen findet sich $\tau \iota$ anstelle von $\tau \varepsilon$; für die in der Boissonade'schen Ausgabe erscheinende Femininform $\mu \alpha v \iota x \eta ́ v$ ist dagegen allein eine überbewertete jüngere korrigierende Hand im Cod.

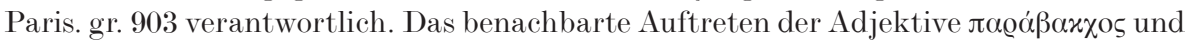
uavıxós - um alle Kasus abzudecken wurden natürlich lediglich die Wortstämme $\pi \alpha \varrho \alpha \beta \alpha x \chi \ldots \mu \alpha v \iota x$ nachgeschlagen - ist laut der CD-ROM des TLG (derzeit gültige Version E) neben der Barlaam-Legende nur bei Skylitzes/Kedrenos und Georgios

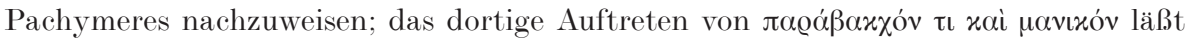
auf eine Verwendung einer Barlaam-Hs. der Modifikationen B, C oder D durch die beiden Historiker schließen, vgl. Ioannis Scylitzae synopsis historiarum. Editio princeps recensuit I. Thurn. Berlin, New York 1973, 20,48 und Georges Pachymérès, Relations historiques, 1. Livres I-III. Édition, introduction et notes par A. FAILLER. Traduction

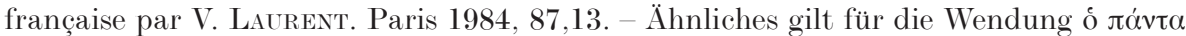
$\beta \lambda \varepsilon \dot{\pi} \omega v$ ỏ $\phi \theta \alpha \lambda \mu$ ós; sie ließ sich auf dieselbe Weise neben der Barlaam-Legende ( $P G$ 96,

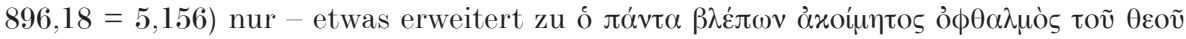
- bei Nicephori Gregorae Byzantina historia cura L. Schopeni, 2. Bonn 1830, 757,16 verifizieren; vgl. auch Nikephoros Gregoras, Rhomäische Geschichte - Historia Rhomaïke, übersetzt und erläutert von J. L. van Dieten, 3. Stuttgart 1988, 351, Anm. 393 , wo der Übersetzer angibt, daß er den Erstbeleg nicht habe feststellen können.

7 Vgl. P. E. Sonnenburg, Franz Buecheler. Jahresbericht über die Fortschritte der klassischen Altertumswissenschaft 155 (1911, ersch. 1912) 139-162; R. MenRlein, Bücheler, Franz. Neue Deutsche Biographie, 2. Berlin 1955, 717.

${ }^{8}$ Eine biographische Darstellung von ihm gibt E. Pfeiffer in P. RabBow, Paidagogia. Die Grundlegung der abendländischen Erziehungskunst in der Sokratik. Aus dem Nachlaß hrsg. von E. Pfeiffer. Göttingen 1960, 285-289. Rabbow promovierte 1897 in Bonn über ein latinistisches Thema. Nicht unvermögend, wirkte er in erster Linie als Privatgelehrter in Göttingen. Zu seinen Verbindungen mit dem Thesaurus Linguae Latinae s. Thesaurus-Geschichten. Beiträge zu einer Historia Thesauri linguae Latinae von Tн. Bögel (1876-1973), hrsg. v. D. Krömer und M. Flieger. Stuttgart und Leipzig 1996, $36-37,43,44,46$ und 218.

9 P. RabBow, Die Legende des Martinian. WSt 17 (1895) 253-293; zudem 1896 als Separatum von 45 Seiten im Selbstverlag erschienen. Die S. 11-18 dieses Separatums 
Mit reicher Dokumentation aus der griechischen und lateinischen Hagiographie behandelt Rabbow ausgiebig das verbreitete Motiv von der Versuchung eines Asketen durch eine Dirne, das in der anschließend von ihm gemeinsam mit P. Wittichen und unter Mithilfe seines Lehrers Hermann Usener (1834-1905) ${ }^{10}$ sowie von H. Schoene, H. Omont und H. Delehaye erstmals edierten Martinian-Legende $(B H G$ 1177) die Spitze und Vollendung $^{11}$ erfahren habe. Besonders verdienstvoll ist Rabbows Heranziehung der damals ebenfalls noch gar nicht gedruckt vorliegenden Umarbeitung der alten Martinian-Legende durch Symeon Metaphrastes (BHG 1178-1179); auch mit dem Barlaam-Roman vertraut, fielen ihm sofort gewisse Gemeinsamkeiten dieser beiden Texte auf, die er nach einigen kommentierenden Worten - Diese Metaphrase hat eine ganz besondere und vielleicht einschneidende Wichtigkeit dadurch, dass sie in die Geschichte des griechischen Barlaam und Joasaph hinübergreift. Man kennt die Scene dieses Romans, in welcher die gefangene Prinzessin den frommen Joasaph seinem Keuschheitsgelübde untreu machen will. Man vergleiche selbst ${ }^{12}$ - synoptisch gegenüberstellt, und die ihn mit völliger Sicherheit zu dem Schluß führen, dass die Benutzung auf Seiten des Metaphrasten ist ${ }^{13}$. Die besondere Bedeutung, die gesicherte BarlaamZitate bei Symeon Metaphrastes, einem Autor oder Redaktor aus der zweiten Hälfte des 10. Jhs., für die Datierung eben der Barlaam-Legende haben müssen, ist Rabbow selbstverständlich bewußt, wenn er formuliert: Bei dem Dunkel, das noch immer über der verwickelten Frage nach Entstehungszeit und Geschichte des Barlaam liegt, ist jede sichere Nachricht hochwillkommen. Die Metaphrase des Martinian, ..., bietet das älteste bisher ermittelte Citat des be-

(= 259-266 im Zeitschriftenband, den ursprünglichen Text enthaltend) existieren zusätzlich in einer stark veränderten editio altera correctior. Der Benutzer des 17. Bandes der WSt - der keine Bücheler-Festschrift darstellt - erfährt aus Rabbows Beitrag lediglich, daß es sich bei ihm um eine Festgabe an einen unbekannt bleibenden Jubilar handelt; nur im seltenen Separatum findet sich auf S. 3 die Widmung Herrn Geheimrat Buecheler zur Feier des Sommersemesters MDCCCXCV in Ehrfurcht und Liebe.

${ }^{10}$ Usener stellte Rabbow seine eigenen Kollationen der Editionshandschriften zur Verfügung und wies seinen Schüler auch auf die Erneuerung der Martinian-Legende durch E. Schaffner, Die Flucht vor dem Weibe. Westermanns Monatshefte 75 (1893/1894) 480-491 hin (vgl. RabBow [wie Anm. 9], Separatum 18 neu, Anm. 52; in der Erstfassung, a.a.O. 266 [= Separatum 18 alt], Anm. 55, fehlt der persönliche Hinweis Useners noch). Die wahre Autorschaft verriet er ihm offenbar nicht - oder Rabbow behielt sie für sich; denn Schaffners altchristliche Novelle ist ein zunächst pseudonym veröffentlichtes Werk von Usener selbst, posthum abgedruckt dann auch in H. Usener, Vorträge und Aufsätze. Leipzig, Berlin 1907 bzw. ${ }^{2} 1914$, 233-259.

11 Rabbow (wie Anm. 9) 277 (Separatum 29).

12 Rabbow (wie Anm. 9) 271 (Separatum 23).

${ }^{13}$ Rabbow (wie Anm. 9) 276 (Separatum 28). 
rühmten Asketenromans in der griechischen Literatur ${ }^{14}$. Und ganz offenbar hat er schon in dieser Richtung weitergeforscht, wenn er anmerkt: Es ist für die Schätzung des Stils des griech. Barlaam ... belehrend, dass eine Anzahl „Stilübungen des Metaphrasten“ von dort stammen ${ }^{15}$; eine weitere Veröffentlichung Rabbows zu dieser Frage ist mir allerdings nicht bekannt.

Ohne daß Rabbows Pionierarbeit beachtet wurde, sprach man erst über ein Vierteljahrhundert später (1923) erneut Gemeinsamkeiten zwischen

${ }^{14}$ Rabbow (wie Anm. 9) 276-277 (Separatum 28-29). - Nicht ganz uninteressant für die Arbeitsweise des Metaphrasten könnte auch ein ganz zufälliger Fund sein. Der Satz, daß der Teufel die Tugend Martinians - eines noch jungen Mannes - nicht ertragen konnte, ist in der alten Martinian-Legende (BHG 1177) zweifellos von der Vita Antonii

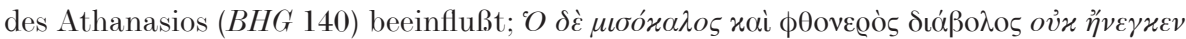

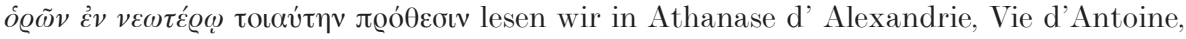
ed. G. J. M. Bartelink (SC 400). Paris 1994, 5,1 (p. 142,1-2). In BHG 1177 lautet dies

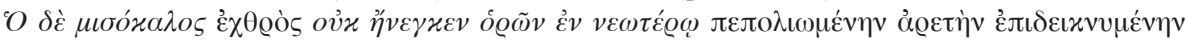

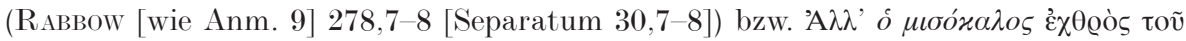

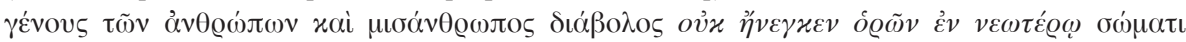

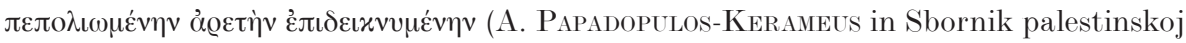
i sirijskoj agiologii, vyp. 1 [Pravoslavnyj Palestinskij Sbornik 57]. St. Petersburg 1907, 86,6-9). Der Metaphrast griff den Gedanken, jedoch kaum die Worte seiner Vorlage

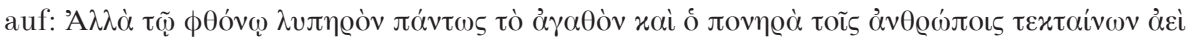

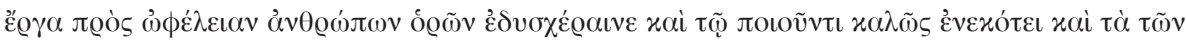

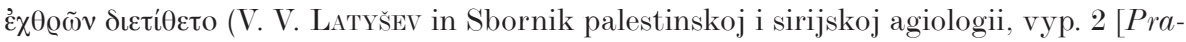
voslavnyj Palestinskij Sbornik 60]. St. Petersburg 1913, 36,17-19). Nach meinem Vortrag auf dem Pariser Byzantinistenkongreß erhielt ich von Herrn Andrej Vinogradov (Moskau) dankenswerterweise den Hinweis, daß Rabbow nicht die älteste MartinianVita ediert habe; diese fände sich vielmehr im Cod. Athous Kutlumus. 38. Über diese von verschiedenen gleichaltrigen Händen des 9.-10. Jhs. geschriebene Handschrift berichtet A. Ehrhard, Überlieferung und Bestand der hagiographischen und homiletischen Literatur der griechischen Kirche von den Anfängen bis zum Ende des 16. Jhs., 3. Leipzig 1943-1952, 734-735. Seine in Scheyern archivierten Aufzeichnungen enthalten weiterführende Informationen zur auf fol. $176^{\mathrm{r}}-186^{\mathrm{r}}$ befindlichen Martinian-Vita;

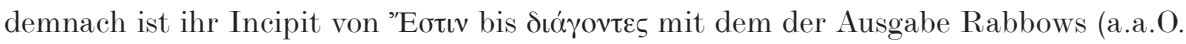

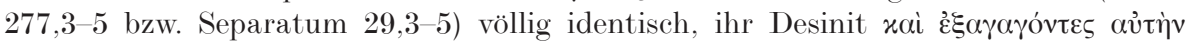

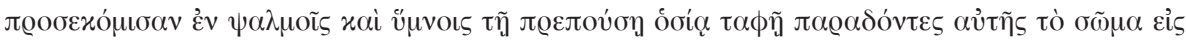

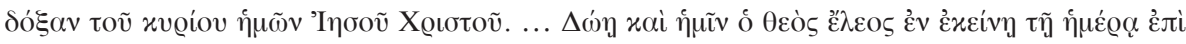

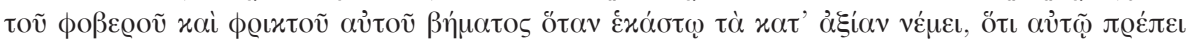
$\delta$ óg $\xi$... ähnelt dagegen nur demjenigen des im Novum Auctarium als BHG $1177 \mathrm{f}$ bezeichneten, im Cod. Thessalonic. Vlat. 7 (s.XI-XII) tradierten, am Anfang stark verstümmelten und nur noch zu etwa zwei Dritteln erhaltenen Textes, ist jedoch - wie wiederum Ehrhards Aufzeichnungen zeigen - länger als dieses. - Zur bereits in einer Handschrift aus dem Jahr 688 existierenden Martinian-Vita in syrischer Sprache s. mit Einführung, Edition und Übersetzung M. van Esbroeck, La Vie de saint Martinianus en version syriaque. Parole de l'Orient 20 (1995) 237-269.

${ }^{15}$ Rabbow (wie Anm. 9) 276, Anm. 68 (Separatum 28). 
einem Text des Symeon Metaphrastes und dem Barlaam-Roman an. Diesmal ging es um die metaphrastische Passio der hl. Katharina (Aecaterina,

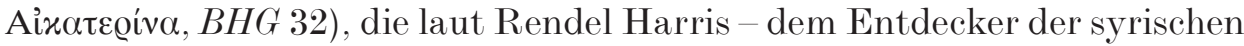
Übersetzung der Apologie des Aristeides - ausgiebig im (!) Barlaam zitiert werde, und die in sich wiederum Material aus einer ansonsten verlorenen frühchristlichen Apologie enthalte ${ }^{16}$. Die den letzten Punkt rasch widerlegenden Kritiker störten sich zurecht daran, daß Harris nicht die längst edierten Vorläufertexte des Metaphrasten über die hl. Katharina ${ }^{17}$ heranzog - und kamen zu dem Schluß, daß der Barlaam-Autor aufgrund des Katharinentextes „C“ (= BHG 31) auch die Passio Catharinae ... in die Form, die wir heute beim Metaphrasten lesen, umgegossen habe, und daß dieser Mann wahrscheinlich ein palästinensischer Mönch gewesen sei ${ }^{18}$. Dölger vermutete in diesem Zusammenhang einen verlorengegangenen Katharinen-Text des Johannes von Damaskus ${ }^{19}$. Inzwischen konnte jedoch nachgewiesen werden, daß Symeon Metaphrastes seine Katharinen-Passio ohne ein verlorenes Zwischenglied unter Heranziehung des Textes „C“ und des Barlaam-Romans geschaffen hat, daß der Text „C“ mit anderen Worten sowohl eine Quelle für bestimmte Teile des Barlaam-Romans als auch Hauptquelle für die Katharinen-Passio des Symeon Metaphrastes ist ${ }^{20}$.

Weitere 70 Jahre später (1995) fiel Maria Spyridonidou-Skarsouli in ihrer kommentierten kritischen Ausgabe einer athonitischen Sammlung

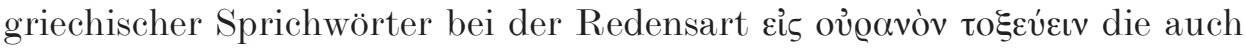
vom Kontext her identische Formulierung des Barlaam-Romans mit der metaphrastischen Passio des Clemens Ancyranus (BHG 353) auf ${ }^{21}$.

${ }^{16}$ Vgl. R. Harris, A new Christian apology. Bulletin of the John Rylands Library Manchester 7 (1923) 355-383, hier 364-370 und 378-382.

${ }^{17}$ Es sind drei, als A, B und C bezeichnet in der Ausgabe von J. Viteau, Passions des saints Écaterine et Pierre d'Alexandrie, Barbara et Anysia, publiées d'après les manuscrits grecs de Paris et de Rome avec un choix de variantes et une traduction latine. Paris 1897, 1-65.

18 Vgl. E. Klostermann und E. Seeberg, Die Apologie der Heiligen Katharina. Berlin 1924, vor allem 19-26 und 56 .

19 Vgl. F. Dölger, Der griechische Barlaam-Roman, ein Werk des h. Johannes von Damaskos. Ettal 1953, 35-37.

${ }^{20}$ Vgl. R. VoLK, Symeon Metaphrastes - ein Benutzer des Barlaam-Romans. RSBN n. s. 33 (1996, ersch. 1998) 67-180, hier 88-111.

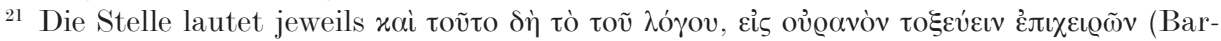
laam, $P G$ 96, 889,8-9 = 5,12-13 und Sym. Met., Pass. s. Clem. Ancyr. c. $75[P G 114$, 877 B 1-2]), vgl. Der erste Teil der fünften Athos-Sammlung griechischer Sprichwörter. Kritische Ausgabe mit Kommentar, hrsg. von M. Spyridonidou-Skarsould (Texte und Kommentare 18). Berlin, New York 1995, 165 2 . 
II.

Die Theorie, daß Symeon Metaphrastes ( $†$ spätestens 987) unter Verwendung der umstrittenen Übersetzung des Euthymios Iber (* kaum vor $955, \dagger 1028)$ vom Georgischen ins Griechische selbst der Barlaam-Autor wäre, ist aufgrund mir im Moment nicht nachprüfbarer Argumente von K. Kekelidze aufgestellt worden ${ }^{22}$; sie erscheint Willem J. Aerts wohl chronologisch unhaltbar ${ }^{23}$. Für die Frage, ob Symeon Metaphrastes Autor oder Bearbeiter des Romans sein könne, zog Aerts zwei von dessen Viten - Ephraims des Syrers (BHG 584) und des Johannes Eleemosynarius (BHG 888) - heran. Beides sind Texte, die nach heutigem Wissen keine frappanten Gemeinsamkeiten mit dem Barlaam aufweisen. Letzterer hat die Johannes-EleëmonVita des Leontios von Neapolis $(B H G$ 886) zur Vorlage, und es läßt sich an vielen Stellen zeigen, wie der Metaphrast die volkstümlichere Sprache des Leontios auf eine mehr hochsprachliche Ebene gehoben hat. Trotzdem kann man sagen, daß Wortwahl und Satzbildung beim Metaphrast im allgemeinen einfacher sind als im Barlaam-Roman, der sich meines Erachtens durch einen sehr großen Sprachreichtum auszeichnet ${ }^{24}$. Auch die posthum erschienene Literaturgeschichte von Alexander Kazhdan (1922-1997 ${ }^{25}$ steuert nicht nur zu dieser Frage, sondern generell zu der oft geäußerten Behauptung, der Barlaam weise Merkmale eines metaphrastischen Stiles auf, der für das späte 10. Jh. typisch sei, gewichtige Gegenargumente bei:

${ }^{22}$ It may even be, as the late Professor K. S. Kekelidze suggested, that Euthymius the Athonite and Simeon Metaphrastes were personally acquainted, and that Euthymius translated the Barlaam romance especially for Simeon's use (D. M. LANG, Introduction, in: St. John Damascene, Barlaam and Ioasaph with an English translation by G. R. WoodWard and H. Mattingly [The Loeb Classical Library 34]. London, Cambridge/Mass. 1967 [u. ö.], IX-XXXV, hier XXXII m. Anm. 1). Der spezielle Aufsatz K. S. KeKelidze, Balavaris romani k'ristianul mdserlobashi (Der Barlaam-Roman in der christlichen Literatur), in: Ders., Etiudebi dzveli k'art'uli literaturis istoriidan (Studien in der Geschichte der altgeorgischen Literatur), 6. Tiflis 1960, 41-71, hier 66-67, war mir bisher nicht zugänglich; in der Bayer. Staatsbibliothek München fehlt leider der 6. Band dieser großen Literaturgeschichte. Daß in ihm über Parallelen zwischen Barlaam-Roman und metaphrastischen Texten diskutiert wird, scheint durchaus möglich.

${ }^{23}$ W. J. Aerts, Einige Überlegungen zur Sprache und Zeit der Abfassung des griechischen Romans „Barlaam und Joasaph“, in: Die Begegnung des Westens mit dem Osten. Kongreßakten des 4. Symposions des Mediävistenverbandes in Köln 1991 aus Anlaß des 1000. Todesjahres der Kaiserin Theophanu. Hrsg. von O. Engels und P. Schreiner. Sigmaringen 1993, 357-364, hier $358 \mathrm{~m}$. Anm. 4.

${ }^{24}$ Aerts (wie Anm. 23) 363.

${ }^{25}$ Vgl. A.-M. Talbot, Alexander Petrovich Kazhdan: The American years. BF 27 (2002) 124-132, hier 131. 
No less hazardous is the claim that the Greek Barlaam was written in the style of Symeon Metaphrastes, typical of the late tenth century when Euthymios the Iberian began his literary career. It hardly requires special study to show that among the vast heritage of the Metaphrastes there is not a single work resembling the Barlaam; what Metaphrastes bequeathed to us are relatively short revisions of vitae produced in different styles and not a Christian romance replete with theological tenets. This brings us back to a point which cannot be stressed too greatly: stylistic similarity is not a reliable basis for dating a piece of Byzantine literature, and in any event the vocabulary of the Barlaam is much closer to that of Damaskenos than that of the Metaphrastes. ${ }^{26}$

\section{III.}

Die Aufspürung von markanten Barlaam-Parallelen im bis vor kurzem nur lateinisch gedruckten Metaphrastentext über den Apostel Thomas (BHG 1835) wurde endgültig zum Ansporn, im Zuge der Editionsarbeiten am Barlaam-Roman nach Möglichkeit das gesamte hagiographische Corpus des Metaphrasten durchzuarbeiten. Erste Ergebnisse, beruhend auf insgesamt 15 Texten - darunter die editio princeps des genannten ThomasTextes BHG 1835 - , konnten 1996 zum Druck gebracht werden ${ }^{27}$.

Inzwischen ist es tatsächlich gelungen, sämtliche hagiographischen Texte des Symeon Metaphrastes nach Parallelen mit der Barlaam-Legende zu durchforsten, und es ergibt sich folgendes Bild:

Der Index der Bibliotheca Hagiographica Graeca verzeichnet 138 Texte des Symeon Metaphrastes, von denen bis auf sechs (BHG 154b; $B H G$ 413m; $B H G$ 799; $B H G$ 932g; $B H G 1067$ und BHG 1148) die Autorschaft als weitgehend gesichert angesehen werden kann, sowie 18 fremde, meist wesentlich ältere Texte, die unverändert in das metaphrastische Menologium übernommen wurden; da in diesem Index aber der sowohl Symeon wie auch Johannes Chrysostomus zugeschriebene Normaltext „Petrus 2" (= BHG 1486) zweimal erscheint, handelt es sich um insgesamt nicht 156, sondern nur um 155 Texte $^{28}$. Hinsichtlich der in ihnen enthaltenen Barlaam-Parallelen lassen sie sich in drei Gruppen einteilen:

${ }^{26}$ A. Kazhdan, A history of Byzantine literature (650-850). In collaboration with L. F. Sherry - C. Angelidi. Athen 1999, 96-97.

27 Volk (wie Anm. 20).

${ }^{28}$ Vgl. Bibliotheca Hagiographica Graeca. $3^{\text {me }}$ édition mise à jour et considérablement augmentée par F. Halkin, 3: Supplément, appendices et tables (Subsidia hagiographica 8a). Brüssel 1957, 263-264. Diese Zahlen ändern sich durch das Novum Auctarium Bibliothecae Hagiographicae Graecae par F. Halkin (Subsidia hagiographica 65a). Brüssel 1984, 388-389, nicht. 
a) keine Barlaam-Parallelen enthaltend;

b) eindeutige Barlaam-Parallelen enthaltend, und

c) unsichere Barlaam-Parallelen enthaltend.

Aufgrunddessen füge ich nun drei Tabellen an, die sich an den Übersichten Ehrhards über die insgesamt 148 Normaltexte des metaphrastischen Menologiums ${ }^{29}$ orientieren, beginnend mit dem September und endend mit dem August.

Als erste sei die Gruppe aufgeführt, die keine auf Anhieb erkennbaren Barlaam-Parallelen aufweist; ich bezeichne sie hier mit A. Sie ist mit 72 unergiebigen Normaltexten die umfangreichste Gruppe und wird noch vergrößert durch sieben nicht im metaphrastischen Menologium enthaltene, eher suspekte Texte, von denen zwei noch unedierte bisher sogar überhaupt nicht gesichtet werden konnten, bei denen aber die Wahrscheinlichkeit, Barlaam-Parallelen zu enthalten, verschwindend gering ist. Ich spreche hier im übrigen von Barlaam-Parallelen, weil verschiedene alte in das metaphrastische Menologium übernommene Texte natürlich keine Zitate aus dem Barlaam enthalten, sondern teilweise schon lange bekannte Quellen für ihn sind, wie etwa die Vita Antonii des Athanasius (BHG 140), oder als solche erst vor kurzem aufgespürt wurden, wie die Vita der Maria Aegyptiaca (BHG 1042).

A 1) - 2. September: Passio des Mamas (BHG 1018).

A 2) - 4. September: Passio des Babylas $(B H G ~ 206)^{30}$.

A 3) - 6. September: Wunder des Erzengels Michael in Chonai (BHG 1284).

A 4) - 7. September: Passio des Sozon (BHG 1644).

A 5) - 9. September: Passio des Severianus (BHG 1627).

A 6) - 10. September: Passio von Menodora, Metrodora und Nymphodora (BHG 1273).

A 7$)$ - 12. September: Passio des Autonomos (BHG 198).

A 8) - 16. September: Passio der Euphemia (BHG 620).

A 9) - 17. September: Passio von Sophia, Pistis, Elpis und Agape (BHG 1638).

A 10) - 19. September: Passio von Trophimos, Dorymedon und Sabbatios (BHG 1854).

${ }^{29}$ Vgl. generell Ehrhard, Überlieferung und Bestand (wie Anm. 14), 2. Leipzig 1938, 306-615.

${ }^{30}$ Vermeintliche Barlaam-Parallelen in diesem Text gehen in Wirklichkeit auf Werke des Johannes Chrysostomos zurück, die auch vom Barlaam-Autor zitiert werden, jedoch nicht derartig ausgiebig wie in $B H G$ 206; s. a. unten, S. 168. 
A 11) - 22. September: Laudatio auf den Gärtner Phokas von Sinope, von Asterios v. Amaseia (BHG 1538-1540, a Metaphrasta in menologium inserta).

A 12) - 27. September: Passio des Kallistratos (BHG 291).

A 13) - 29. September: Vita des Anachoreten Kyriakos (BHG 464).

A 14) - 1. Oktober: Passio des Apostels Ananias (BHG 76).

A 15) - 4. Oktober: Passio der Charitina (BHG 300).

A 16) - 8. Oktober: Vita der Pelagia (BHG 1479).

A 17) - 10. Oktober: Passio von Eulampios und Eulampia (BHG 617).

A 18) - 13. Oktober: Passio von Karpos, Papylos und Agathonike (BHG 295).

A 19) - 14. Oktober: Passio von Nazarios und Gefährten (BHG 1324).

A 20) - 15. Oktober: Passio des Lukianos (BHG 997).

A 21) - 16. Oktober: Passio des Centurio Longinus (BHG 989).

A 22) - 19. Oktober: Passio des Andreas in Crisi (BHG 112).

A 23) - 20. Oktober: Passio des Artemios (BHG 172).

A 24) - 25. Oktober: Passio von Markianos und Martyrios (BHG 1029).

A 25) - 28. Oktober: Passio der Anastasia von Rom $(B H G \text { 77 })^{31}$.

${ }^{31}$ Die vermeintliche Barlaam-Parallele in diesem Text geht wohl direkt auf ein Werk des Johannes Chrysostomos zurück, das auch vom Barlaam-Autor zitiert wird: In Kap. 16 des metaphrastischen Anastasia-Textes wird der Heiligen die Zunge abgeschnitten, und man schlägt ihr die Zähne ein; aus ihrem Mund fließt Blut und färbt ihre Kleidung rot

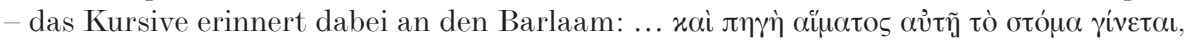

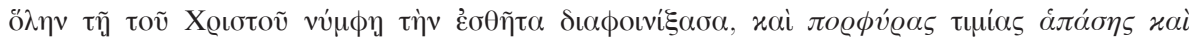

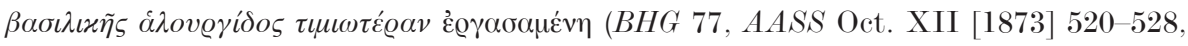
hier 527 A 19-20). In der mutmaßlichen Vorlage des Metaphrasten, verfaßt von Niketas

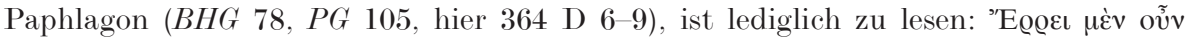

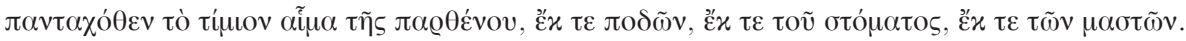

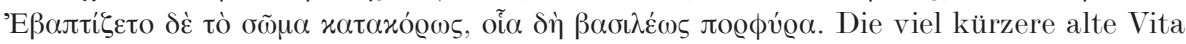
BHG 76z erwähnt zwar den Blutstrom aus dem Mund, nicht jedoch seine färbende Wirkung, gleiches gilt auch für $B H G$ 76x. Man vergleiche daher die mutmaßliche Bar-

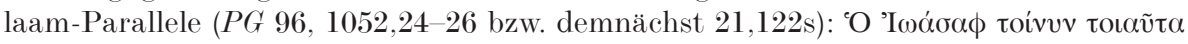

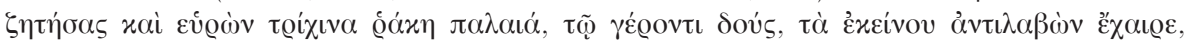

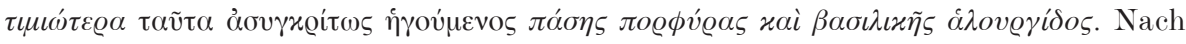
Konsultierung des $T L G$ scheint die zitierte $B H G$ 77-Stelle jedoch eher von der Laudatio auf die Martyrerin Pelagia aus der Hand des Johannes Chrysostomos $(B H G 1477=$ $C P(4350)$ beeinflußt zu sein; das Kriterium ist vor allem das im Barlaam fehlende

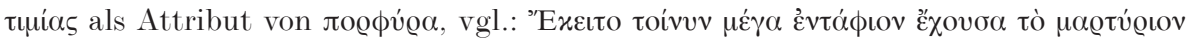

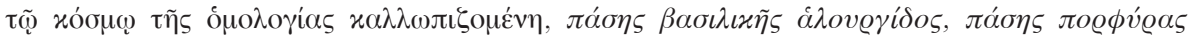

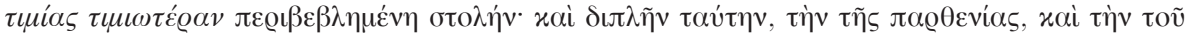

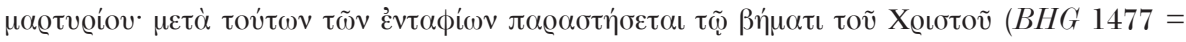
$C P G$ 4350, $P G$ 50, 582,33-39). Die Autorschaft des Johannes Chrysostomos für diesen Pelagiatext bezweifelt im übrigen S. J. VoICU, Pseudo-Giovanni Crisostomo: I confini del corpus. JbAC 39 (1996) 105-115, hier 107. 
A 26) - 29. Oktober: Vita von Abramios und Maria (BHG 8).

A 27) - 31. Oktober: Passio des Epimachos (BHG 594).

A 28) - 1. November: Vita und Passio von Kosmas und Damian (BHG $374)$.

A 29) - 2. November: Passio des Akindynos, Pegasios und Gefährten $(B H G$ $23)$.

A 30) - 3. November: Passio von Akepsimas, Ioseph und Aeithalas (BHG 20).

A 31) - 5. November: Passio von Galaktion und Episteme (BHG 666).

A 32) - 6. November: Vita des Paulus Confessor (BHG 1473).

A 33$)$ - 7. November: Passio des Hieron (BHG 750).

A 34) - 9. November: Vita der Matrona von Perge $\left(B H G\right.$ 1222) ${ }^{32}$.

A 35$)$ - 10. November: Vita der Theoktiste von Lesbos (BHG 1725-1726).

A 36$)$ - 18. November: Passio des Platon von Ankyra (BHG 1551-1552 $)^{33}$.

A 37$)$ - 23. November: Vita des Amphilochios von Ikonion (BHG 72).

A 38) - 25. November: Clementis Romani Epitome de gestis Petri altera auctore Symeone Metaphrasta (BHG 345-347).

A 39$)$ - 25. November: Passio des Petrus Alexandrinus (BHG 1503).

A 40) - 26. November: Passio des Mercurius ( $B H G$ 1276).

A 41) - 26. November: Vita des Alypios Stylites (BHG 64).

A 42) - 7. Dezember: Vita des Ambrosius von Mailand (BHG 69).

A 43) - 8. Dezember: Vita des Patapios (BHG 1424).

A 44) - 10. Dezember: Passio von Menas, Hermogenes und Eugraphos (BHG 1271).

A 45) - 12. Dezember: Vita des Spyridon ( $B H G$ 1648).

A 46) - 14. Dezember: Passio von Thyrsos und Gefährten ( $B H G$ 1845$1846)$.

A 47$)$ - 15. Dezember: Passio des Eleutherios (BHG 571).

A 48) - 17. Dezember: Commentarius auf den Propheten Daniel (BHG 485).

A 49) - 23. Dezember: Passio der 10 Martyrer von Kreta (BHG 1197).

A 50) - 24. Dezember: Passio der Eugenia (BHG 608).

A 51) - 28. Dezember: Passio von Indes und Domna (BHG 823).

32 Bereits behandelt bei VoLk (wie Anm. 20) 172.

33 Noch unediert. In $P G$ 115, 404-425 ist versehentlich die Vorlage des Metaphrasten (BHG 1549-1550) ediert worden (aus Cod. Paris. gr. 1539 [s.X-XI], fol. 37-50), deren Prolog mit den gleichen Worten beginnt. Konsultiert wurde daher für den Metaphrastentext der Cod. Monac. gr. 179 (ein November-Menologion), fol. 26 ${ }^{\mathrm{v}}-32$ (s.XI, die einen Blattausfall ergänzenden fol. 27-30 [s.XIII] enthalten ebenfalls den Metaphrastentext). 
A 52) - 29. Dezember: Vita des konstantinopolitanischen AkoimetenArchimandriten Marcellus (BHG 1028).

A 53) - 31. Dezember: Vita der Melania (BHG 1242).

A 54) - 10. Januar: Vita des konstantinopolitanischen Oikonomos Markianos $(B H G \text { 1034) })^{34}$.

A 55) - 13. Januar: Passio von Hermylos und Stratonikos (BHG 745).

A 56) - 16. Januar: Rede auf Petri Kettenfeier $(B H G 1486=C P G$ $4745)^{35}$.

A 57) - 22. Januar: Passio des Apostels Timotheus (BHG 1848).

A 58) - 22. Januar: Passio des Anastasius Persa $(B H G 85)^{36}$.

A 59) - 24. Januar: Vita der Eusebia, genannt Xene $(B H G$ 634).

A 60) - 25. Januar: Vita des Gregor v. Nazianz $(B H G 723=C P G 7975$, von Gregorios Presbyter, a Metaphrasta in menologium inserta).

A 61) - 27. Januar: Commentarius auf die Translation der Reliquien des Johannes Chrysostomos (BHG 877).

A 62$)$ - 31. Januar: Vita von Kyros und Johannes (BHG 471).

A 63) - 8. Februar: Vita des Lucas iunior (BHG 994, a Metaphrasta in menologium inserta).

A 64) - 9. Februar: Passio des Nikephoros (BHG 1332).

A 65) - 11. Februar: Passio des Blasius (BHG 277).

A 66) - 6. März: Passio der 42 Martyrer von Amorion, von Euodios (BHG 1214, a Metaphrasta in menologium inserta).

A 67) - 26. April: Laudatio auf den Bischof von Amaseia Basileus (BHG 240, a Metaphrasta in menologium inserta).

A 68) - 17. Juni: Passio von Manuel, Sabel und Ismael (BHG 1024).

A 69) - 27. Juni: Vita des konstantinopolitanischen Xenodochos Sampson (BHG 1615).

A 70) - 29. Juni: Commentarius über die Apostel Petrus und Paulus (BHG 1493).

A 71) - 29. Juli: Passio des Kallinikos v. Gangra (BHG 287).

A 72) - 16. August: Rede über die Translation des Christusbildes von Edessa nach Konstantinopel $(B H G$ 794-795, gehalten von Konstantin Porphyrogennetos, a Metaphrasta in menologium inserta).

Die ebenfalls keine Barlaam-Parallelen enthaltenden Nummern A 73) bis A 79) sind keine Normaltexte des metaphrastischen Menologiums:

34 Bereits behandelt bei VoLK (wie Anm. 20) 172.

35 Wohl ein Text des Johannes Chrysostomos, den Symeon fast unverändert in sein Menologium übernahm, weil die - guten - stilistischen Eigenschaften ihn zufriedengestellt haben dürften.

36 Bereits behandelt bei VoLK (wie Anm. 20) 172. 
A 73) - Index über die Apostel (BHG 154b; aus der Chronik des Symeon Logothetes, unklare Autorschaft).

A 74) - Synaxarium metricum auf das Kreuz Christi (BHG 413m; Autorschaft unsicher) ${ }^{37}$.

A 75) - Epitome über Gregor v. Nazianz (BHG 730e; e Symeonis Metaphras-

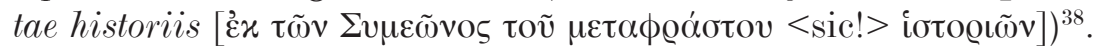

A 76) - Miraculum in puteo magnae ecclesiae et narratio de mago Mesita (BHG 799; Autorschaft unsicher; angeblich von Symeon Logothetes).

A 77) - Rede auf den Evangelisten Johannes (BHG 932g; Symeon Magistros Logothetes zugeschrieben) ${ }^{39}$.

A 78) - Commentarius auf das Bild Mariens in Rom (BHG 1067; Autorschaft unsicher) ${ }^{40}$.

A 79) - In lugubrem lamentationem Mariae (BHG 1148; Autorschaft unsicher $)^{41}$.

${ }^{37}$ Mit Vorbehalt hier eingereiht, da noch unediert und noch nicht gesichtet. Der Text - im

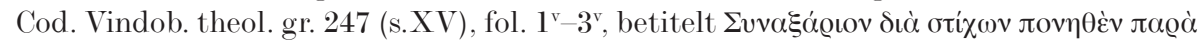

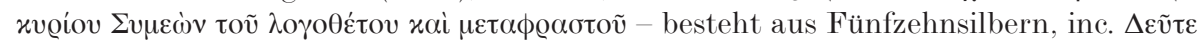

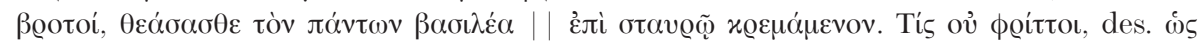

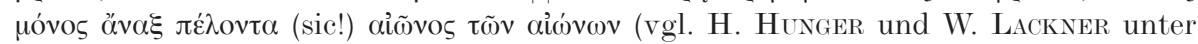
Mitarbeit von C. Hannick, Katalog der griechischen Handschriften der Österreichischen Nationalbibliothek, 3/3: Codices theologici 201-337. Wien 1992, 161-162). Zwei weitere Zeugen nennt das neue Auctarium der BHG: Cod. Paris. gr. 1595 (s.XV), fol. $156^{\mathrm{r}}-158^{\mathrm{v}}$ und Cod. Olympiotissae 132.

${ }^{38}$ Mit Vorbehalt hier eingereiht, da noch unediert und noch nicht gesichtet. Es handelt

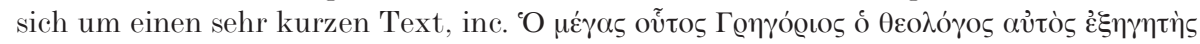

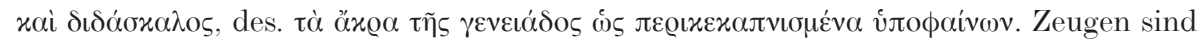
die Codd. Vat. Ottobon. gr. 447, fol. $2^{\text {rv }}$ (s.XV) und Cantabrig. coll. s. Trinit. 1173 (O 3.1; s.XVI), fol. 2; zu letzterem vgl. Ehrhard, Überlieferung und Bestand (wie Anm. 14), 3, 1004, Anm. 5 von S. 1003. Daß ein Exzerpt aus der unedierten Chronik Symeons vorliegen könnte (vgl. Ehrhard, Überlieferung und Bestand [wie Anm. 14], 2, 703, Anm. 4 von S. 702), scheint eher unwahrscheinlich, denn die Erwähnungen Gregors v. Nazianz in ihrer slavischen Übersetzung sind noch wesentlich knapper, vgl. Die Chronik des Symeon Metaphrastes und Logothetes. Nachdruck der slavischen Übersetzung in der Ausgabe von V. I. SreznevskiJ mit einer Einleitung von R. Zетт. München 1971, 45-47 passim. Eine Suche nach den Begriffen $\gamma \varepsilon v \varepsilon\llcorner\alpha \ldots$... xaлv auf der CD-ROM des TLG (Version E) war erfolglos.

39 Noch unediert im codex unicus (vgl. a. Ehrhard, Überlieferung und Bestand [wie Anm. 14], 2, 702, Anm. 4), dem Monac. gr. 226 (s.XIII), fol. 106 ${ }^{r}-108^{\text {r }}$; in Scheyern als Film vorhanden. Sie bietet stilistisch keinerlei Kriterien, die auf Symeon Metaphrastes hindeuten; streckenweise ist sie ein Frage- und Antwort-Text.

${ }^{40}$ Stilistisch wirkt der Text nicht metaphrastisch.

${ }^{41}$ Heute maßgeblich ediert von W. Hörandner, Der Prosarhythmus in der rhetorischen Literatur der Byzantiner. Wien 1981, 91-111. Der Text stammt mit hoher Wahrscheinlichkeit von Nikephoros Basilakes (12. Jh.). 
Die zweite Gruppe, ich bezeichne sie hier mit B, ist die interessanteste, denn sie enthält eindeutige und teilweise sehr lange und zahlreiche Barlaam-Parallelen. Es handelt sich ausschließlich um Normaltexte, und es sind insgesamt 46 :

B 1) - 15. September: Passio des Goten Niketas (BHG 1340).

B 2) - 20. September: Passio von Eustathios (Placidas) und Gefährten $(\text { BHG 642 })^{42}$.

B 3$)$ - 24. September: Acta der Thekla $(B H G 1719)^{43}$.

B 4) - 26. September: Commentarius auf den Apostel und Evangelisten Johannes (BHG 919).

B 5) - 30. September: Vita des Gregorius Illuminator von Armenien (BHG $713)$.

B 6) - 2. Oktober: Passio des Cyprianus und der Iustina (BHG 456).

B 7) - 3. Oktober: Passio des Dionysius Areopagita (BHG 555).

B 8) - 6. Oktober: Commentarius auf den Apostel Thomas $(B H G 1835)^{44}$.

B 9) - 7. Oktober: Passio von Sergius und Bacchus (BHG 1625).

B 10) - 12. Oktober: Passio von Probus, Tarachus und Andronicus (BHG $1575)$.

B 11) - 18. Oktober: Commentarius auf den Apostel und Evangelisten Lukas (BHG 991).

B 12) - 19. Oktober: Passio von Varus, Cleopatra und Gefährten (BHG 1863).

B 13) - 21. Oktober: Vita des Hilarion $(B H G 755)^{45}$.

B 14) - 22. Oktober: Vita des Abercius $(B H G 4)^{46}$.

B 15) - 24. Oktober: Passio des Arethas $(B H G 167)^{47}$.

${ }^{42}$ Dieser Text existiert in georgischer Übersetzung von Euthymios dem Iberer im Cod. 1104, fol. 114-126, des Georgischen Nationalmuseums zu Tbilisi sowie dem Cod. 5, fol. 236-256, von Gelat'i und dem Cod. 6, fol. 114-126, der Elias-Kapelle auf dem Athos, vgl. M. Tarchnišvili in Verbindung mit J. Assfalg, Geschichte der kirchlichen georgischen Literatur, auf Grund des ersten Bandes der georgischen Literaturgeschichte von K. Kekelidze bearbeitet (Studi e Testi 185). Vatikanstadt 1955, 149, Anm. 5.

${ }_{43}$ Bereits behandelt bei Volk (wie Anm. 20) 124-131.

${ }^{44}$ Erstmals ediert und behandelt bei VoLK (wie Anm. 20) 145-171.

${ }^{45}$ Noch nicht vollständig ediert. Für die in der auf 21 Hss. beruhenden, sehr gründlichen Teiledition von R. F. Strout und G. Steiner in Studies in the text tradition of St. Jerome's Vitae Patrum by J. F. Cherf [u. a.], ed. by W. A. Oldfather with the assistance of M. D. McNeIL [u. a.]. Urbana 1943, 402-406 fehlenden Passagen wurde der Cod. Monac. gr. 443 (s.XIV-XV), fol. $236^{\mathrm{v}}-256^{\mathrm{r}}$ herangezogen.

${ }^{46}$ Bereits behandelt bei Volk (wie Anm. 20) 111-113.

${ }^{47} \mathrm{Zu}$ diesem Text liegt inzwischen mit M. Detoraki, La métaphrase du Martyre de S. Aréthas $(B H G$ 166y). Entre les Actes anciens (BHG 166) et Syméon Métaphraste 
B 16) - 26. Oktober: Passio des Demetrios (BHG 498).

B 17) - 30. Oktober: Passio von Zenobios und Zenobia $(B H G 1885)^{48}$.

B 18) - 4. November: Vita des Ioannikios $(B H G 937)^{49}$.

B 19) - 11. November: Passio des Menas in Ägypten (BHG 1250).

B 20) - 13. November: Vita des Johannes Chrysostomos (BHG 875) $)^{50}$.

B 21) - 14. November: Commentarius auf den Apostel Philippus (BHG $1527)$.

(BHG 167). AnBoll 120 (2002) 72-100 eine hochaktuelle Studie vor. Sie zeigt überzeugend, daß die direkte Vorlage von $B H G 167$ weder der alte Text $B H G 166$, noch - wie bisher vermutet (vgl. Ehrhard, Überlieferung und Bestand [wie Anm. 14], 1, 465 ${ }^{14}$ und

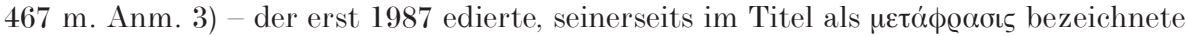
Text $B H G$ 166z (einziger Zeuge Cod. Paris. Coisl. gr. 110 [s.XI], fol. 131 ${ }^{\mathrm{r}}-145^{\mathrm{r}}$, ed. F. Halkin, Six inédits d'hagiologie byzantine. Brüssel 1987, 133-157) ist, sondern vielmehr der bis auf einige Proben bei Detoraki a. a. O. noch unedierte Text BHG 166y (einziger Zeuge Cod. Athous Protat. 2 [s.XI], fol. $110^{r}-120^{\mathrm{v}}$ ), der nach den handschrift-

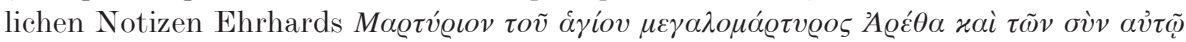
$\mu \alpha \varrho \tau$. überschrieben ist. Dagegen sei $B H G 166 \mathrm{z}$ vom Metaphrastentext $B H G 167$ abhängig und verkürze diesen. Mit anderen Worten: Es dürfte der Protaton-Text BHG 166y, um Vorlage von Symeon Metaphrastes sein zu können, höchstwahrscheinlich keine Barlaam-Parallelen enthalten, was im Moment nicht nachgeprüft werden kann. Wenden wir uns dennoch kurz den markantesten Barlaam-Parallelen im Metaphrastentext $B H G 167 \mathrm{zu}$, die demnach in der nachmetaphrastischen Bearbeitung $B H G 166 \mathrm{z}$ mehr oder weniger deutlich erscheinen müßten: 1) In cap. 7, PG 115, 1256 D 3-5 stimmen die kursiv gedruckten Worte aus der wörtlichen Rede eines christenfeindlichen Königs

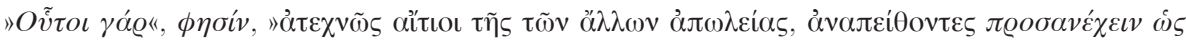

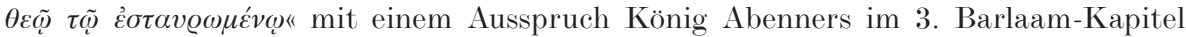
überein $(P G 96,880,48-49$ bzw. demnächst 3,43-44). Der zitierte Satz aus $B H G 167$ findet sich in der Tat bis auf das Wort $\dot{\alpha} \tau \varepsilon \chi v \tilde{\omega} \varsigma$ vollständig in der Metaphrase $B H G 166 \mathrm{z}$ (ed. Halkin, p. 138,3-5). 2) Auch die kursiv gedruckten Worte aus cap. 7, PG 115, 1256

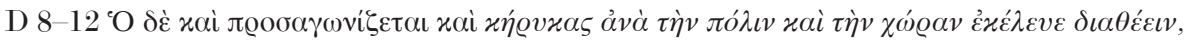

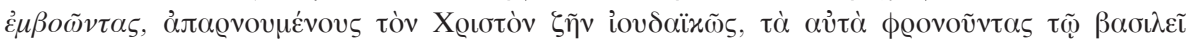
finden sich einige Zeilen früher im 3. Barlaam-Kapitel ( $P G 96,880,43-44$ bzw. demnächst 3,39-40). Geringfügig verkürzt erscheint der zitierte Satz auch in der Metaphra-

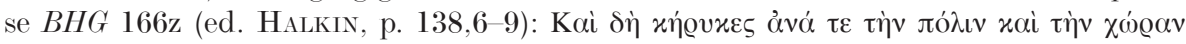

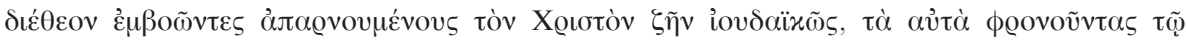

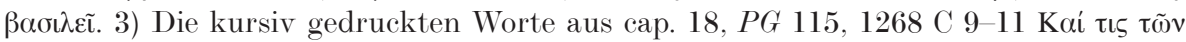

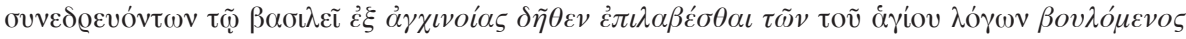
sind auch im 4. Barlaam-Kapitel vorhanden ( $P G$ 96, 888,25-26 bzw. demnächst 4,135136). Diese Wendung ist in der Metaphrase BHG 166z (ed. Halkin, p. 144,27-28) stark

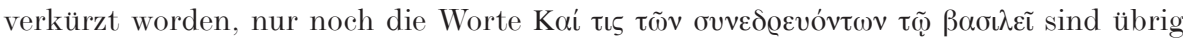
geblieben.

48 Bereits behandelt bei Volk (wie Anm. 20) 113-115.

49 Bereits behandelt bei Volk (wie Anm. 20) 120-124.

${ }^{50} \mathrm{Zu}$ diesem Text s. a. unten, S. 165-168. 
B 22) - 16. November: Commentarius auf den Apostel und Evangelisten Matthaeus (BHG 1226).

B 23) - 17. November: Laudatio auf Gregorius Thaumaturgus v. Neocaesarea, von Gregor v. Nyssa (BHG 715, a Metaphrasta in menologium inserta $)^{51}$.

B 24) - 24. November: Passio der Aecaterina (BHG 32$)^{52}$.

B 25$)$ - 28. November: Vita des Stephanus iunior $(B H G 1667)^{53}$.

B 26) - 30. November: Commentarius auf den Apostel Andreas (BHG 101).

B 27$)$ - 4. Dezember: Passio der Barbara $(B H G 216)^{54}$.

B 28) - 13. Dezember: Passio von Eustratios und Gefährten (BHG 646,a Metaphrasta in menologium inserta $)^{55}$.

B 29) - 19. Dezember: Passio von Sebastianus und Gefährten (BHG 1620).

B 30) - 20. Dezember: Passio des antiochenischen Bischofs Ignatius (BHG $815)$.

B 31) - 5. Januar: Vita des Paulus Thebaeus $(B H G \text { 1468 })^{56}$.

B 32) - 9. Januar: Passio des Polyeuctus $(B H G \text { 1568 })^{57}$.

B 33) - 14. Januar: Narratio des Nilus Ancyranus über die Martyrermönche vom Sinai und von Raithu (recensio metaphrastica, $B H G$ 1307b) ${ }^{58}$.

B 34$)$ - 15. Januar: Vita des Johannes Calybita (BHG 869) ${ }^{59}$.

B 35$)$ - 17. Januar: Vita des Antonius, von Athanasius (BHG 140, a Metaphrasta in menologium inserta $)^{60}$.

B 36) - 23. Januar: Passio des Clemens Ancyranus ( $B H G$ 353 $)^{61}$.

B 37) - 1. Februar: Passio des Tryphon (BHG 1857).

B 38$)$ - 7. Februar: Passio des Theodoros Stratelates (BHG 1752).

${ }^{51}$ Dieser alte Text stellt eine Quelle für die Barlaam-Legende dar.

${ }^{52}$ Bereits behandelt bei Volk (wie Anm. 20) 88-111.

53 Bereits behandelt bei Volk (wie Anm. 20) 138-145.

${ }_{54}$ Bereits behandelt bei Volk (wie Anm. 20) 131-134.

55 Dieser alte Text stellt eine Quelle für die Barlaam-Legende dar, s. unten, S. 157-158.

${ }_{56}$ Die Vorlage des Metaphrasten ist auch Quelle für die Barlaam-Legende, s. unten, S. $156-157$.

57 Bereits behandelt bei Volk (wie Anm. 20) 135-138. Die Vorlage des Metaphrasten ist auch Quelle für die Barlaam-Legende, s. unten, S. 154-156.

${ }_{58}$ Die Vorlage des Metaphrasten ist auch Quelle für die Barlaam-Legende.

59 Bereits behandelt bei Volk (wie Anm. 20) 116-120.

${ }^{60}$ Dieser alte Text ist seit langem als Quelle für die Barlaam-Legende bekannt s. unten, S. 157. Er existiert in georgischer Übersetzung von Euthymios dem Iberer im Cod. 79, fol. 268ff., des Georgischen Nationalmuseums zu Tbilisi, vgl. Tarchnišvili / Assfalg (wie Anm. 42) 149, Anm. 4.

${ }^{61}$ Dieser Text existiert in georgischer Übersetzung von Euthymios dem Iberer im Cod. 1 von Martvili auf fol. 101-105, vgl. Tarchnišvili / Assfalg (wie Anm. 42) 149, Anm. 6. 
B 39) - 13. Februar: Vita des Martinian $(B H G \text { 1178-1179 })^{62}$.

B 40) - 17. Februar: Passio des Theodoros Teron (BHG 1763).

B 41) - 9. März: Passio der 40 Martyrer von Sebaste ( $B H G$ 1202).

B 42) - 1. April: Vita der Maria Aegyptiaca, zugeschrieben dem Sophronios von Jerusalem $(B H G 1042=C P G$ 7675, a Metaphrasta in menologium inserta $)^{63}$.

B 43) - 23. April: Passio des Georgius (BHG 677 $)^{64}$.

B 44) - 8. Juli: Passio des Procopius (BHG 1579) ${ }^{65}$.

B 45) - 27. Juli: Passio des Arztes Panteleemon (BHG 1414).

B 46) - 1. August: Commentarius auf die Makkabäer (BHG 1006, dem Flavius Iosephus zugeschrieben, a Metaphrasta in menologium insertus $)^{66}$.

Die dritte und letzte Gruppe schließlich, ich bezeichne sie hier mit C, ist es etwas kleiner. Es handelt sich um 30 Normaltexte, die unsichere Barlaam-Parallelen enthalten, teilweise reine Floskeln, bei denen es aber nicht

${ }^{62}$ Bereits behandelt bei Volk (wie Anm. 20) 70-88.

${ }^{63}$ Dieser alte Text stellt eine wichtige Quelle für die griechische Barlaam-Legende dar, s. unten, S. 158-160. Er existiert in georgischer Übersetzung, angeblich von Euthymios dem Iberer, im Cod. 272, fol. 91-105, des Georgischen Nationalmuseums zu Tbilisi (vgl. Tarchnišvili / Assfalg [wie Anm. 42] 149, Anm. 2) sowie in den Codd. Hieros. georg. 2 (s.XI), fol. $142^{\mathrm{v}}-156^{\mathrm{r}}$, und 36 (s.XIII-XIV), fol. $69^{\mathrm{v}}-77^{\mathrm{v}}$, hier dem auf fol. $77^{\mathrm{v}}-$ $107^{\mathrm{v}}$ folgenden ältesten vollständigen Vertreter der verkürzten georgischen BarlaamVersion Sibrdzne Balahvarisi vorangehend (vgl. R. P. Blake, Catalogue des manuscrits géorgiens de la Bibliothèque patriarcale grecque à Jerusalem. ROC 23 [1922-1923] $345-413 ; 24$ [1924] 190-210; 387-429; 25 [1925-1926] 132-155, hier 361 und 192; dort jedoch in beiden Fällen kein Hinweis auf die Übersetzung speziell von Euthymios).

${ }^{64} \mathrm{Zu}$ diesem wohl zu Unrecht umstrittenen Text, der übrigens auch in georgischer autographer Übersetzung von Euthymios dem Iberer aus dem Jahr 990 existiert, s. unten, S. $151-154$.

${ }^{65} \mathrm{Ob}$ es wirklich dieser Metaphrastentext ist, der in georgischer Übersetzung von Euthymios dem Iberer im Cod. 1103 des Georgischen Nationalmuseums zu Tbilisi und in einer 1912 noch unkatalogisierten Oxforder Hs. aus dem 11. Jh. auf fol. 217-241 existiert, ist m. E. zweifelhaft. Das von Tarchnišvilu / Assfalg (wie Anm. 42) 148, Anm. 5 mitgeteilte Incipit In jenen Tagen, als Diokletian und Maximian in Rom die Herrschaft innehatten erinnert eher an die Vorlage $B H G$ 1578; P. Peeters, De codice hiberico Bibliothecae Bodleianae Oxoniensis. AnBoll 31 (1912) 301-318, hier 310 (Nr. 19), übersetzt Incipit und Desinit - die in Vorlage und Metaphrase anfangs ohnehin relativ ähnlich sind - nicht und läßt die Frage nach der griechischen Vorlage durch die Angabe $=B H G^{2}$ 15\%8-15\%9 völlig offen.

${ }^{66}$ Dieser auch als 4. Makkabäerbuch bezeichnete alte Text ist ergiebige Quelle für einen Teil des 23. Kapitels der Barlaam-Legende. 
auszuschließen ist, daß sie letzten Endes mit dem Barlaam-Roman in Verbindung stehen könnten:

C 1) - 1. September: Vita des Symeon Stylites (BHG 1686-1687).

C 2) - 3. September: Passio des Bischofs Anthimus (BHG 135).

C 3) - 6. September: Passio von Romulus, Eudoxius, Zeno und Macarius (BHG 1604).

C 4) - 11. September: Vita der Theodora v. Alexandrien, genannt Theodorus $(B H G$ 1730).

C 5) - 13. September: Passio des Centurio Cornelius (BHG 371).

C 6) - 25. September: Vita der Euphrosyne (BHG 626).

C 7) - 28. September: Vita des Abtes Chariton (BHG 301).

C 8) - 23. Oktober: Commentarius auf den Apostel Iacobus, den Herrenbruder (BHG 764).

C 9) - 12. November: Vita des Ioannes Eleemosynarius (BHG 888).

C 10) - 15. November: Passio von Gurias, Samonas und Abibos (BHG 736-738).

C 11) - 24. November: Vita des Gregorios v. Agrigent, von Niketas Paphlagon (BHG 708, a Metaphrasta in menologium inserta).

C 12) - 27. November: Passio des Iacobus Persa (BHG 773 $)^{67}$.

C 13) - 5. Dezember: Vita des Sabas (BHG 1609).

C 14) - 6. Dezember: Vita des Nikolaus von Myra (BHG 1349).

C 15) - 11. Dezember: Vita des Daniel Stylites (BHG 490).

C 16) - 18. Dezember: Passio des Bonifatius $\left(B H G\right.$ 281-282 ${ }^{68}$.

C 17) - 21. Dezember: Passio der Iuliana (BHG 963).

C 18) - 22. Dezember: Passio der Anastasia von Rom (BHG 82).

C 19) - 27. Dezember: Vita des Theodorus Graptus (BHG 1746).

C 20) - 11. Januar: Vita des Theodosius coenobiarcha (BHG 1778).

C 21) - 18. Januar: Vita des Athanasius von Alexandria (BHG 183).

C 22) - 20. Januar: Vita des Abtes Euthymios (BHG 649).

C 23) - 26. Januar: Vita des Xenophon (BHG 1878).

C 24) - 28. Januar: Vita von Ephraim dem Syrer (BHG 584).

C 25) - 7. Februar: Passio des Parthenios von Lampsakos (BHG 1423).

C 26) - Samstag der 5. Fastenwoche: Text über den Hymnos Akathistos (BHG 1060, a Metaphrasta in menologium insertum).

C 27$)$ - 8. Mai: Vita des Arsenios (BHG 168, a Metaphrasta in menologium

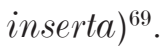

${ }^{67}$ Noch unediert; durchgearbeitet im Cod. Monac. gr. 179 (s.XI), fol. 151 $1^{\mathrm{r}}-157^{\mathrm{r}}$.

${ }_{68}$ Bereits behandelt bei Volk (wie Anm. 20) 115-116.

${ }^{69}$ Die Wahrscheinlichkeit, daß es sich hier um einen echten Metaphrastentext handelt, ist hoch; s. unten, S. 161. 
C 28) - 31. Juli: Vita des Eudokimos (BHG 607).

C 29) - 15. August: Commentarius auf Leben, Tod und Kleidung Mariens (BHG 1047-1048).

C 30) - 29. August: Commentarius auf Johannes d. Täufer (BHG 835$837)$.

IV.

Die Häufigkeit von Barlaam-Parallelen in Metaphrasten-Texten der 2. Gruppe ist ganz unterschiedlich. Sie reicht von wenigen relativ kurzen Übereinstimmungen in verschiedenen Texten bis zu weit über 20, oft viele Zeilen lang, in den beiden Rekordhaltern - den Viten des Paulus Thebaeus (BHG 1468) und Gregorius' des Erleuchters von Armenien (BHG 713). Aus letzterer sei ein besonders langes Beispiel gegeben - man beachte jeweils den Kursivdruck:

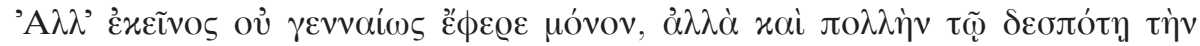

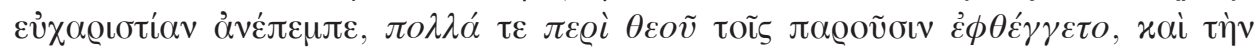

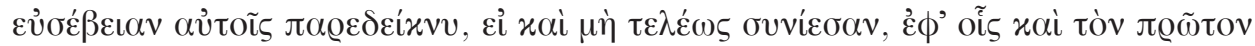

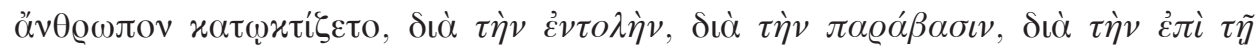

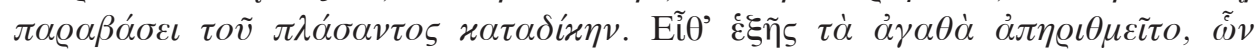

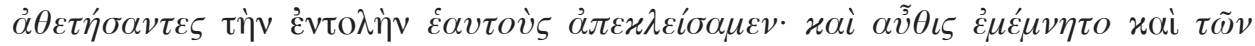

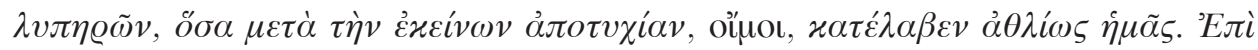

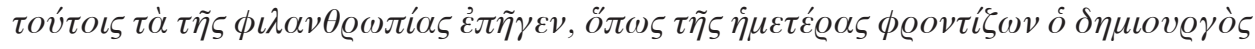

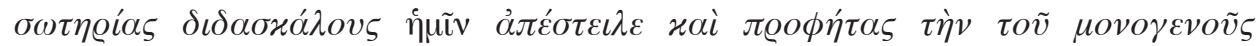

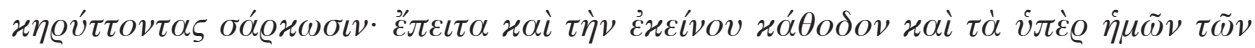

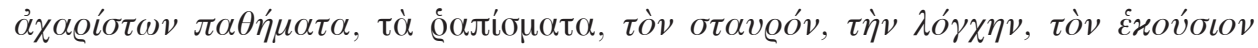

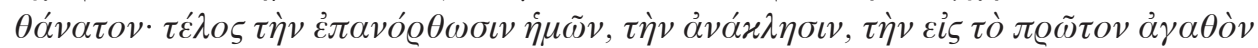

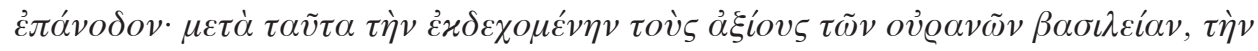

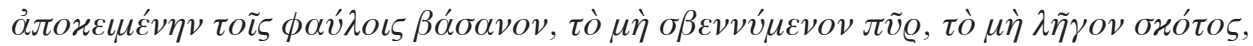

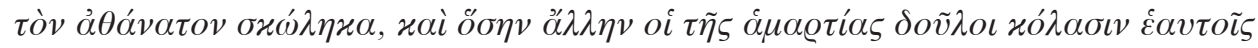

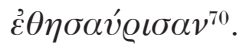

Und nun die Entsprechung im 21. Barlaam-Kapitel:

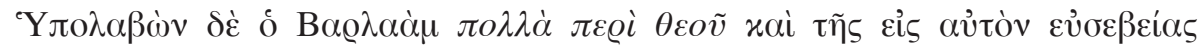

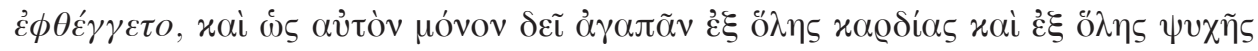

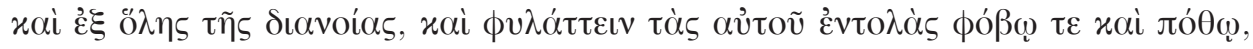

${ }^{70}$ Symeon Metaphrastes, Vita s. Gregorii Illuminatoris c. 10, ed. P. De Lagarde, Die Akten Gregors von Armenien neu herausgegeben, Abhandlungen der Königlichen Gesellschaft der Wissenschaften zu Göttingen 35 (1888, ersch. 1889) 89-120, hier 96, 19-34. 


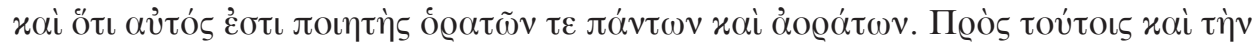

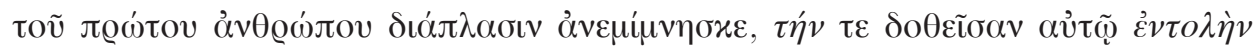

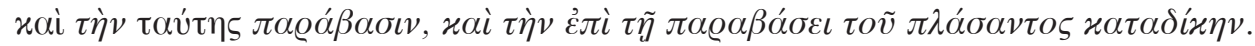

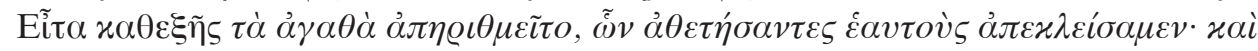

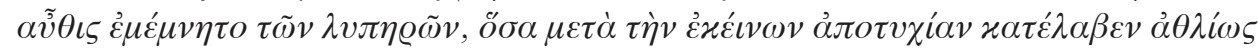

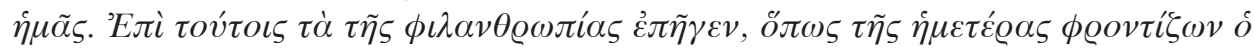

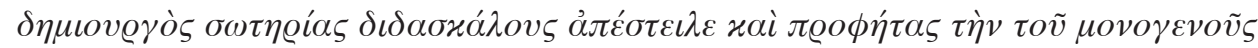

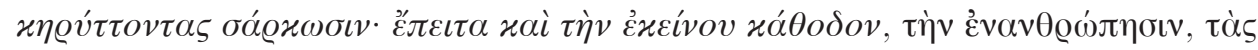

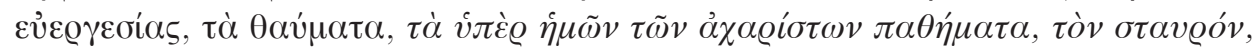

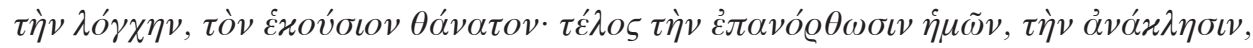

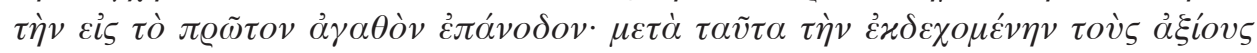

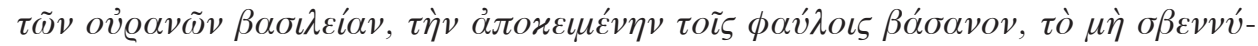

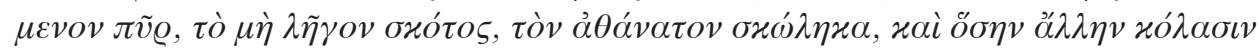

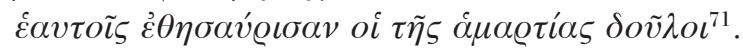

In allen Fällen, bei denen die Vorlagen der Metaphrasen bekannt sind - die Vorlage BHG 712 der gerade angesprochenen metaphrastischen Gregorius-Vita enthält übrigens keinen vergleichbaren Passus -, läßt sich sicher nachweisen, daß die Barlaam-Parallelen in den Metaphrasen tatsächlich Zitate aus dem Barlaam-Roman darstellen. Es ist aber heute noch mehr möglich - etwa eine genaue Eingrenzung des Barlaam-Textes, der von Symeon Metaphrastes und seinem Team benutzt wurde. Es konnte bereits vor einigen Jahren (1994) gezeigt werden, daß der griechische BarlaamRoman in einer urtextnahen Form und in vier Modifikationen existiert, und auch der Wert dieser fünf Textgruppen konnte erörtert werden ${ }^{72}$. Inzwischen ist die Feinarbeit am Stemma weiter fortgeschritten, und es ist zu bemerken, daß alle diese Textgruppen uns noch heute in Handschriften etwa ab dem Jahr 1000 vorliegen - entweder in kompletten Codices oder partienweise in alten Zeugen mit kontaminiertem Text ${ }^{73}$. Daß Symeon Metaphrastes bzw. sein Team sich stets desselben, heute nicht mehr vorhandenen Zeugen der eher zweitrangigen Barlaam-Modifikation B bediente, wird aus sehr vielen Details ersichtlich. Aufgrund neuerschlosse-

71 Text der entstehenden Barlaam-Neuausgabe 21,23-42, entspricht weitgehend PG 96, $1045,36-1048,19)$.

72 Vgl. R. Volk, Urtext und Modifikationen des griechischen Barlaam-Romans. Prolegomena zur Neuausgabe. BZ 86/87 (1993/94) 442-461.

73 Der Cod. Athous Batoped. 384 aus dem frühen 11. Jh. wechselt bei stets gleicher Schreiberhand, die zusätzlich noch zahlreiche Randkorrekturen beisteuert, blockweise zwischen den Modifikationen B, A, dem Urtext und der Modifkation D. Der stark verkürzte Text der Modifikation C existiert mit dem Cod. Athous Iber. 463 ebenfalls schon in einer Handschrift des 11. Jhs., jedoch nie in kontaminierten Textzeugen. 
nen metaphrastischen Materials seien hier zwei markante Beispiele angeführt:

1.) Im 4. Kapitel des ohne unmittelbare Vorlage zusammengestellten Kommentars auf den Apostel und Evangelisten Johannes (BHG 919) lesen wir, bezogen auf die Bevölkerung der Insel Patmos:

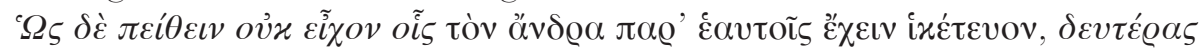

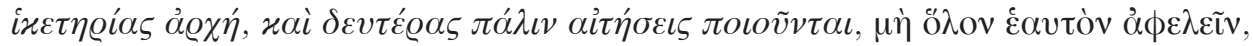

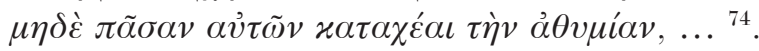

Man vergleiche die ganz ähnliche Passage aus dem 21. Kapitel des Barlaam-Romans in der Ausgabe von Boissonade und achte dabei auf das

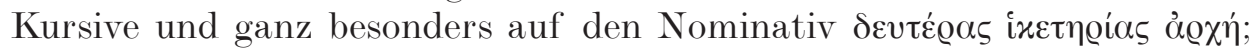
Barlaam möchte die Rückreise in die Wüste antreten und hat soeben abgelehnt, für seine Mitbrüder und für sich selbst von Ioasaph Geschenke anzunehmen. Prinz Ioasaph macht einen zweiten Überredungsversuch, was dort folgendermaßen lautet:

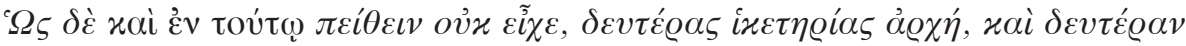

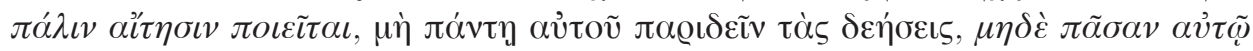

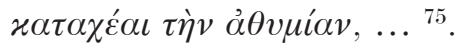

Daß die überflüssig, in ihrem Nominativ sogar widersinnig wirkenden

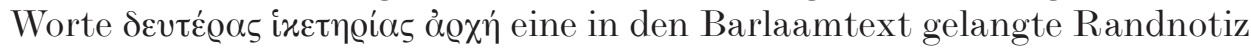
sein könnten, vermutete bereits der Erstherausgeber Boissonade, denn er fand sie nur im Cod. Paris. gr. 903 vor, nicht jedoch in seiner zweiten Editionshandschrift, dem Paris. gr. 1128 ${ }^{76}$. Er hätte sie, meint Boissonades Kommentator Johann Heinrich Christian Schubart (1800-1885), ohne Bedenken ... als Glossem streichen können, indem sie sich fast handgreiflich als solches zu erkennen geben ${ }^{77}$, fand sie jedoch selbst in einem Teil der von ihm kollationierten Wiener Handschriften. Sie fehlen nämlich stets in Handschriften der Modifikationen A und D, die ansonsten einen mit Boissonade weitgehend identischen Text bieten. In der urtextnahen Textgruppe, der nicht zuletzt die älteste datierte Barlaam-Handschrift, der Cod. Kiev. Bibl. Acad. Scient. Ucrain. V 3692 (a.1021) angehört, und der die neue Ausgabe

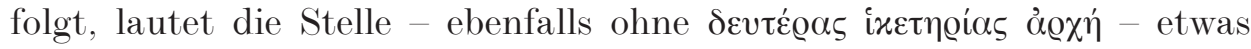
anders, denn sie leitet eine in den späteren Modifikationen umschriebene direkte Rede ein:

${ }^{74} P G$ 116, 692 C 9-13.

${ }^{75} P G$ 96, 1052,6-9 entsprechend Boissonade p. 184-185.

${ }^{76}$ Vgl. Volk, Urtext (wie Anm. 72) 450 m. Anm. 34.

77 J. H. C. Schubart, Historia Barlaami et Joasaph, im vierten Bande der Anecdota Graeca von Boissonade, Paris 1832. Jahrbücher der Literatur 63 (Wien 1833) 44-83; 72 (1835) 274-288; 73 (1836) 176-203, hier 275. 


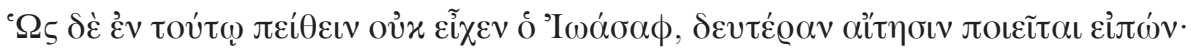

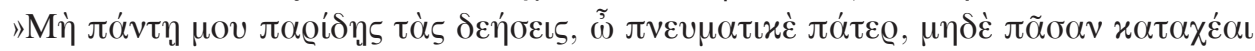

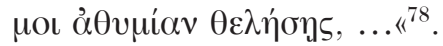

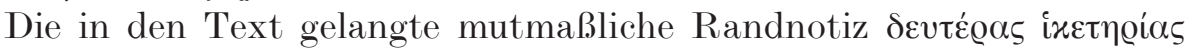

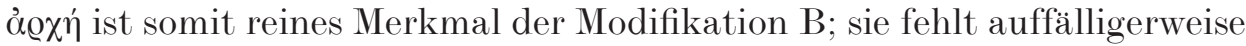
nur in einem einzigen zur Edition herangezogenen Vertreter dieser Textgruppe, nämlich dem Cod. Paris. gr. 1771 (s.XV), der Handschrift, die ohne jegliche Manipulation am Lemma den Barlaam-Roman dem Georgier Euthymios vom Berg Athos zuschreibt. Sie vertritt die Modifikation B auch anderweitig in der besten Form, was die Möglichkeit zumindest nicht ausschließt, daß eventuell Euthymios diese Redigierung nach Wiederentdekkung des georgischen Balavariani unter ständiger Heranziehung von Barlaamtexten der urtextnahen Form und der Modifikation A vorgenommen hat, auch wenn der zeitliche Rahmen dafür sehr eng ist. Wie auch immer - Symeon Metaphrastes benutzte für die in seine Umarbeitungen übernommenen Zitate aus dem Barlaam-Roman stets einen Text der BarlaamModifikation B, der aber nicht an die hohe Qualität heranreicht, wie sie der Cod. Paris. gr. 1771 mit seinem Euthymios-Lemma verkörpert. Die unter Zuhilfenahme der Modifikation B erarbeitete Modifikation C stammt von einem aufmerksamen Redaktor, der bei seiner rigorosen Straffung des ganzen Textes grammatische Zweifelhaftigkeiten niemals übernahm. Auf ganz

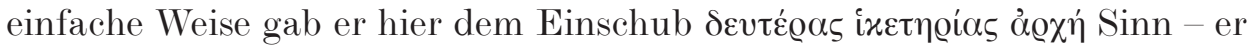
verschob den Akzent und verwandelte ein Substantiv in ein Verbum, so daß der Satz nun folgendermaßen lautet:

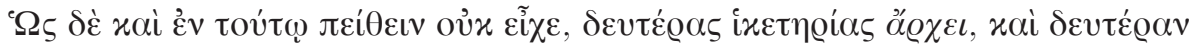

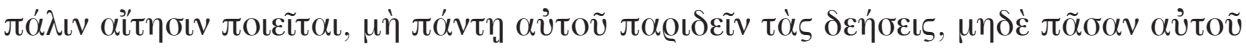

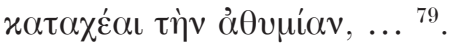

2.) Im 3. Kapitel der metaphrastischen Passio des hl. Demetrius (BHG 498) lesen wir:

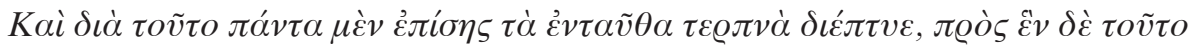

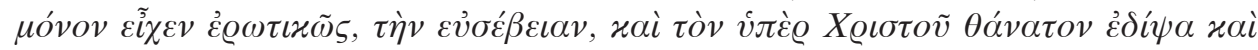

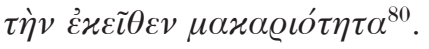

Das Kursive entspricht zu 100\% dem 1. Barlaam-Kapitel in der reinen, bisher ungedruckten Modifikation B, wie ihn in diesem Bereich der schon erwähnte Cod. Athous Batoped. 384 präsentiert, vgl.:

\footnotetext{
78 Barlaam-Neuausgabe 21,108-110.

$79 \mathrm{Vgl}$. Volk, Urtext (wie Anm. 72) 451.

${ }^{80}$ PG 116, 1188 A 5-8.
} 


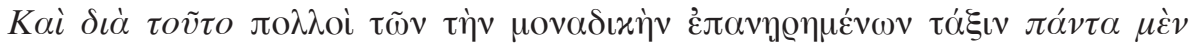

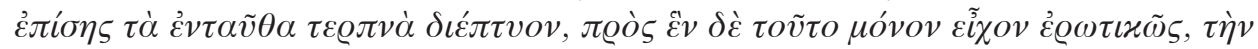

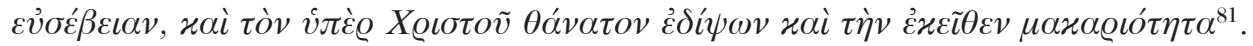

Nur in dieser Handschrift findet sich wie beim Metaphrasten die Wort-

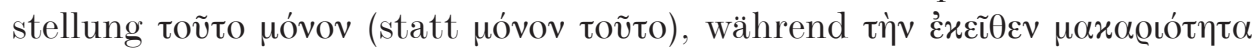
generell ein typisches Merkmal der Modifikation B ist; die urtextnahe

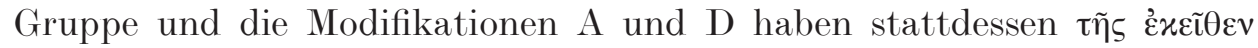

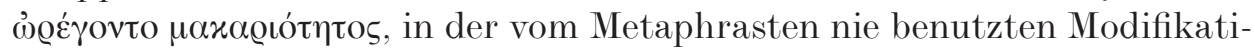
on $\mathrm{C}$ ist dieser ganze Passus den Kürzungsbestrebungen ihres Redaktors zum Opfer gefallen.

David Marshall Lang war die Verwendung eines relativ genau eingrenzbaren Exemplars der Modifikation B des Barlaam-Romans durch Symeon Metaphrastes natürlich noch ganz unbekannt; seine Annahme aber ist zur Gewißheit geworden - obwohl er einen ganz anderen Zusammenhang vermutete und sich nicht zu Barlaam-Zitaten oder -parallelen bei Symeon Metaphrastes äußerte, von denen er bestenfalls durch den oben in Anm. 22 genannten Aufsatz von Kekelidze wußte: There was ample opportunity for a copy to fall into the workshop of Simeon Metaphrastes and his disciples, who will have regarded it as welcome grist to their literary mill. ${ }^{82}$

V.

Möglicherweise können Barlaam-Zitate bei der Klärung der Autorschaft umstrittener Metaphrastentexte mithelfen. Ein solcher Fall liegt bekanntlich mit der Passio des hl. Georg vor. Bereits Allatius (1586/88-

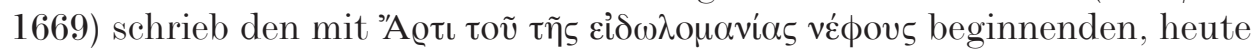
als $B H G 677$ bezeichneten Text dem Symeon Metaphrastes zu ${ }^{83}$. Ehrhard stellte jedoch fest, daß die meisten, und vor allem die ältesten noch erhaltenen Exemplare des hier ausschlaggebenden, vom Februar bis April reichenden 9. Bandes des metaphrastischen Menologiums - diese sind Hand-

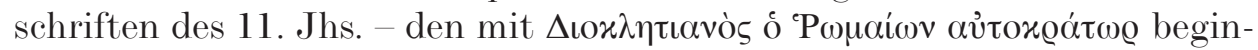
nenden Text BHG 676 enthalten. Er stamme von Niketas David, der wohl mit Niketas Paphlagon gleichzusetzen ist, und sei mit BHG 675z identisch; für die Übernahme in das metaphrastische Menologium sei lediglich der Prolog des Niketas David weggelassen worden ${ }^{84}$. Der Normaltext des me-

${ }^{81}$ Vgl. PG 96, 865,11-15 und Barlaam-Neuausgabe 1,62-65.

${ }^{82}$ LANG, Introduction (wie Anm. 22) XXXII.

${ }^{83} \mathrm{Vgl} . P G$ 114, 123 D.

${ }^{84}$ Vgl. Ehrhard, Überlieferung und Bestand (wie Anm. 14), 2, 610-611; s. a. bereits K. Krumbacher, Der heilige Georg in der griechischen Überlieferung. Vorgetragen am 
taphrastischen Menologiums wäre demnach vom Metaphrasten nur verkürzt und inseriert, und es empfehle sich methodologisch nicht ... , einen Text, der erst vom 12. Jahrhundert an in metaphrastischen Hss auftritt, als vom Metaphrasten selbst verfaßt anzuerkennen ${ }^{85}$. Allerdings sind beide Texte

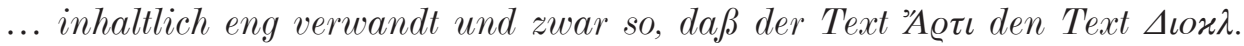
voraussetzt. Es wäre also denkbar, daß der Metaphrast zuerst den von Niketas zubereiteten Text $\Delta$ เoxג. aufnahm, dann aber mit Hilfe dieses Textes und des

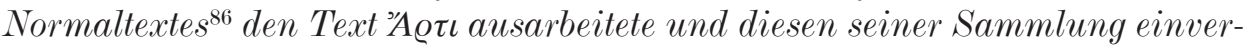
leibte ${ }^{87}$. Genau diese Schlußfolgerung wird durch das Barlaam-Zitat im Text "A@л (BHG 677) gestützt. Man vergleiche in seinem 23. Kapitel die Szene, in der der heilige Georg vor einem großen heidnischen Publikum eine Apollon-Statue befragt, ob sie ein Gott sei, und vom innewohnenden bösen Geist, der unfreiwillig die Wahrheit verkündet, die Antwort erhält, daß nur Christus der wahre Gott sei:

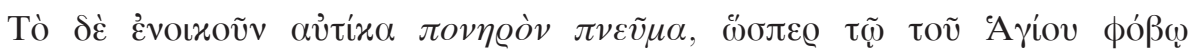

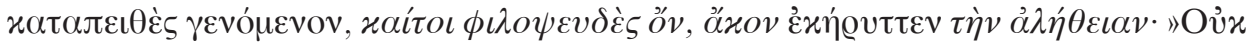

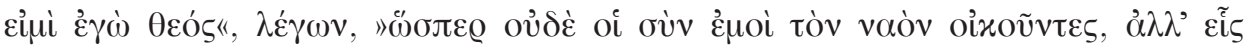

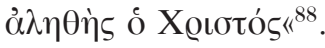

Der Passus enthält die hier kursiv gedruckten Elemente aus dem 31. Barlaam-Kapitel, in dem die vom Zauberer Theudas ausgesandten bösen Geister zu diesem zurückkehren und ihre Niederlage eingestehen:

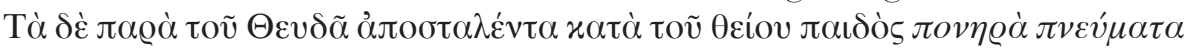

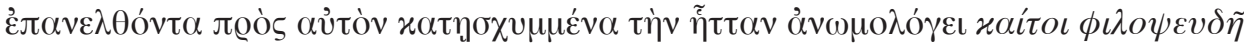

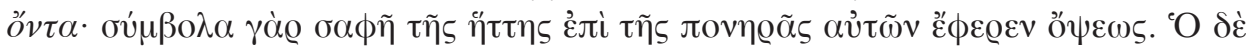

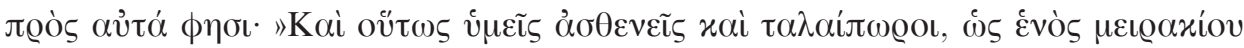

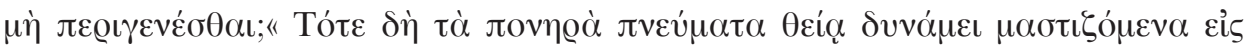

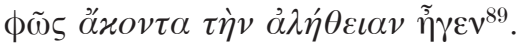

Dagegen lautet die entsprechende, den Text $B H G 677$ durchaus beeinflussende - man vergleiche die kursiv gedruckten Anfangsworte -, jedoch keine Anklänge aus dem Barlaam aufweisende Passage im 22. Kapitel von $B H G 676$ lapidar:

2. Mai 1908. Aus dem Nachlasse des Verfassers herausgegeben von A. Ehrhard (Abhandlungen der Kgl. Bayer. Akademie der Wissenschaften. Philosoph.-philolog. u. histor. Klasse 25.3). München 1911, 184 und 191.

${ }_{85}$ Ehrhard, Überlieferung und Bestand (wie Anm. 14), 2, 611.

${ }^{86}$ Damit ist BHG 671-672 gemeint; der Metaphrast hätte dann nach zwei Vorlagen über den hl. Georg gearbeitet.

${ }^{87}$ Krumbacher (wie Anm. 84) 195.

${ }^{88} P G 115,157$ C 10-14.

89 Barlaam-Neuausgabe 31,4-10, das Kursive im wesentlichen identisch in $P G \quad 96$, 1153,16-24. 


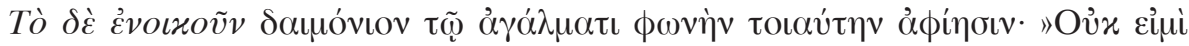

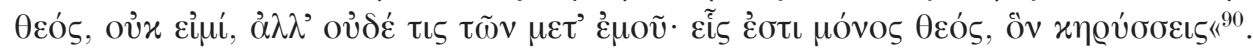

Auch die unbestreitbar zweite Vorlage des Metaphrasten, BHG 671-672, enthält keine Barlaam-Parallelen; das sicher daraus vom Metaphrasten Übernommene ist kursiv gedruckt, vgl.:

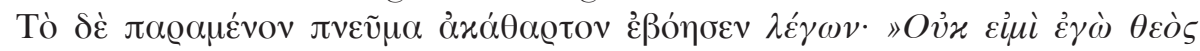

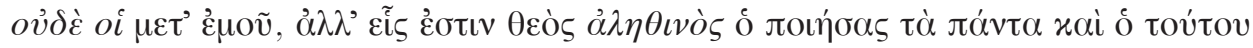

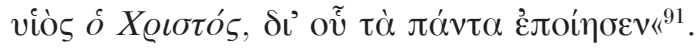

BHG 677 könnte demnach ein nach Fertigstellung des metaphrastischen Menologiums nachgereichter Text und daher wohl eine der spätesten Schöpfungen Symeons und seines Teams sein; bezeichnenderweise wurde ja des öfteren in Codices des 9. Menologium-Bandes der Text BHG 676 entfernt und durch $B H G 677$ ersetzt $^{92}$. Eine besonders interessante Dimen-

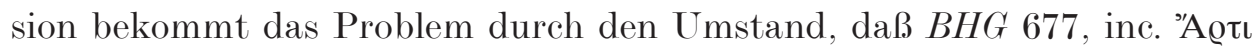

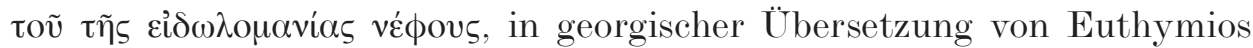
Iber in einer autographen Handschrift desselben aus dem Jahr 990 (!) existiert; betitelt ist der georgische Text (in französischer Übertragung) Passion du saint et glorieux martyr du Christ Georges, écrite par Syméon le Logothète, laquelle se lit dans la plupart des églises de la Grèce, parce que celle-là (= l'autre) est blâmée à cause de son obscuritée $e^{93}$.

$\mathrm{Zu}$ bemerken bleibt, daß sich im elektronischen Thesaurus Linguae

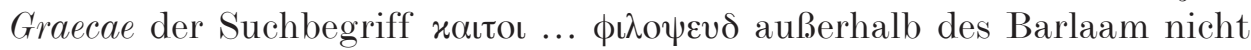
nachweisen ließ und somit die Übernahme dieser barlaamspezifischen Wendung in zwei weitere metaphrastische Texte als gesichert gelten kann. Es handelt sich zunächst um das 6. Kapitel der Passio des Tryphon (BHG 1857); die Rede ist dort von einem bösen Geist, der in Gestalt eines Hundes

${ }^{90}$ AASS April. III (1675) XIV C 7-10.

${ }^{91}$ Krumbacher (wie Anm. 84) 49,23-25.

${ }_{92} \mathrm{Vgl}$. Ehrhard, Überlieferung und Bestand (wie Anm. 14), 2, $597^{7} ; 598^{12} ; 599^{15} ; 600^{18}$; $645 ; 646^{3} ; 647^{5} ; 652^{11} ; 655$.

${ }_{93}$ Darauf aufmerksam wurde ich durch D. M. Lang, St. Euthymius the Georgian and the Barlaam and Ioasaph romance. Bulletin of the School of Oriental and African Studies 17 (1955) 306-325, hier 314-315, wo a much abridged selection of some of Euthymius's translations which are still extant mit einigen vagen, aber vielversprechenden Literaturhinweisen gegeben wird. Der einzige Metaphrastentext dieser Lang'schen Liste ist Simeon Logothetes: Passion of St. George. In R. P. Blake, Catalogue des manuscrits géorgiens de la bibliothèque de la Laure d'Iviron au Mont Athos. ROC 28 (1931-1932) 289-361; 29 (1933-1934) 114-159 und 225-271, hier 262-264, war die Suche danach erfolgreich: Die georgische Übersetzung von $B H G 677$ findet sich im Cod. Athous Iber. georg. 79, enthaltend ouvres variées traduites par saint Euthyme: autographe même du saint. Écrit à l'Athos en 990, auf fol. $98^{\mathrm{r}}-128^{\mathrm{v}}$. Dieses Übersetzungswerk des Euthymios fehlt in Tarchnišvili / Assfalg (wie Anm. 42) 148-149. 
erscheint und mit den kursiv gedruckten Worten aus dem Barlaam-Roman charakterisiert wird:

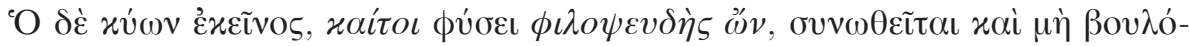

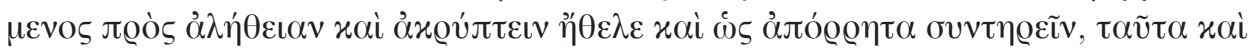

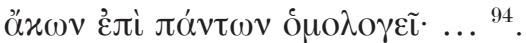

Sie fehlen in der noch unedierten Vorlage $B H G$ 1856z, die mit dem Metaphrastentext identisch beginnt und endet, und aus der ihrerseits die kursiv gedruckten Worte übernommen wurden:

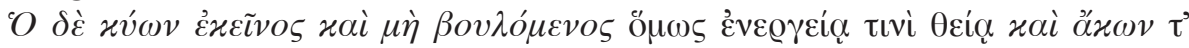

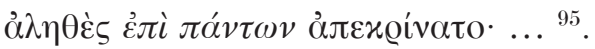

Ganz allgemein eine Fundgrube für Barlaam-Übernahmen, deren Behandlung hier viel zu weit führen würde, ist dann die Passio des Cyprianus

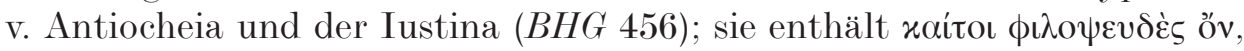
wiederum bezogen auf einen bösen Geist, in ihrem 13. Kapitel ${ }^{96}$.

\section{VI.}

Die Durchsicht der Metaphrastentexte führte mehrfach auch zur Aufdeckung der gemeinsamen alten Vorlage - d. h., der Barlaam-Autor wie auch Symeon Metaphrastes verarbeiteten an gewissen Stellen denselben alten Text. Gemeinsame Quelle für beide Autoren ist, wie schon 1996 gezeigt, die als Text „C“ bezeichnete vormetaphrastische Katharinen-Passio. Ähnlich verhält es sich mit den Passionen des Polyeuktos; zunächst seien hier die Parallelen zwischen dem neu erstellten Barlaamtext und dem Metaphrastentext (BHG 1568) kursiv, solche zwischen Barlaam und dem alten Polyeuktos-Text (BHG 1566-1567) unterstrichen, und das wörtliche NTZitat zusätzlich fett gedruckt:

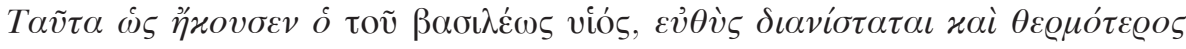

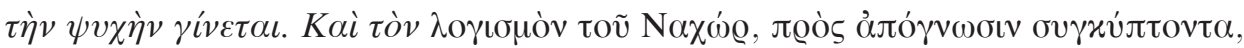

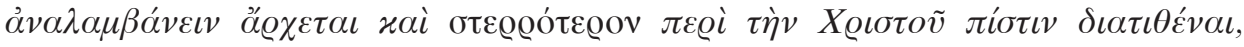

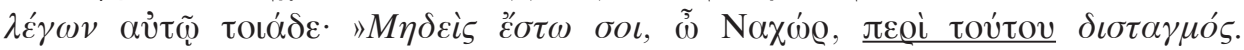

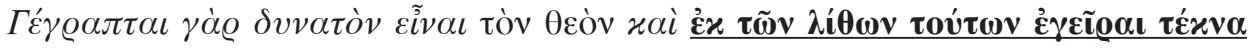

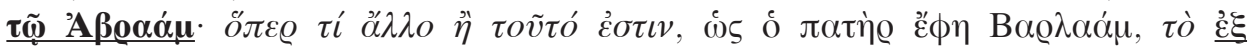

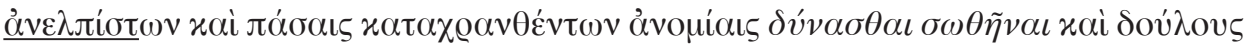

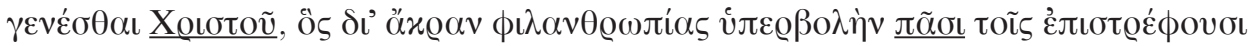

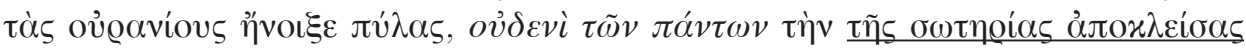

94 PG 114, 1316 D 6-9.

95 Hier zitiert nach dem in Scheyern als Film vorhandenen Cod. Hieros. Sab. 30 (s.X-XI), fol. $275^{\mathrm{r}}$ I, letzte Zeile - II, 4. Zeile.

96 Vgl. $P G$ 115, 860 B 5. 


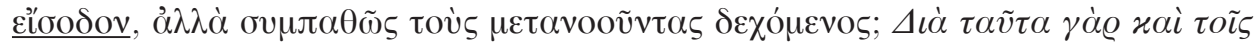

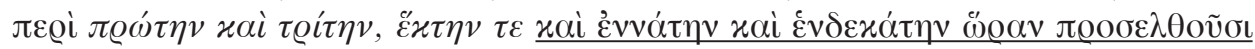

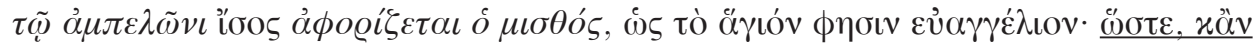

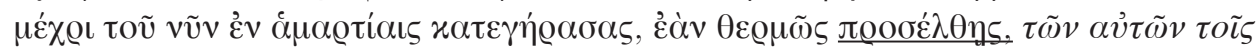

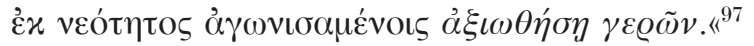

Man vergleiche das 7. Kapitel der metaphrastischen Polyeuktos-Passio:

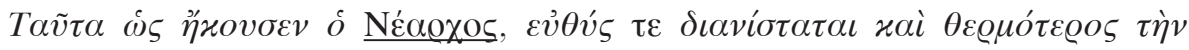

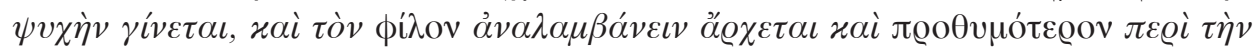

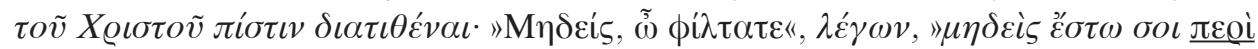

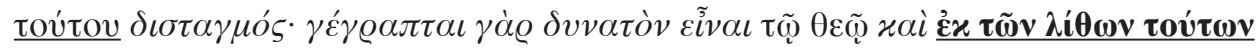

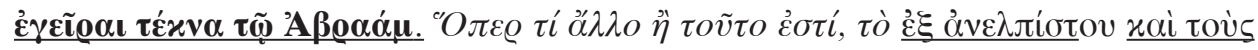

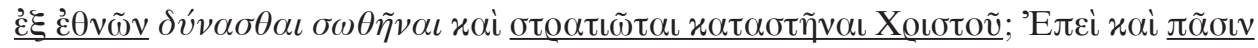

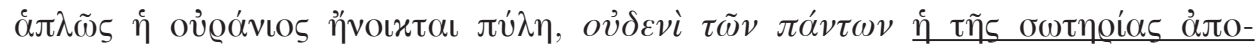

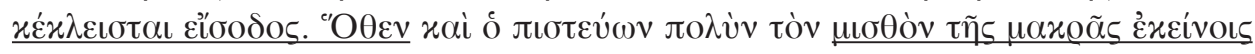

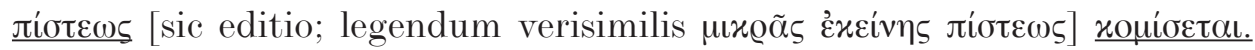

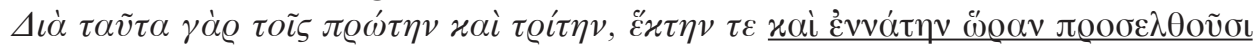

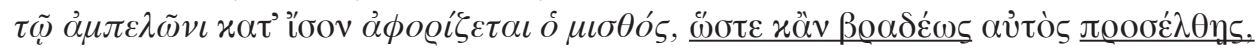

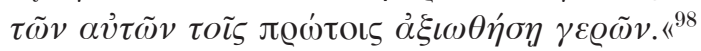

Und schließlich die alte Polyeuktos-Passio (BHG 1566-1567):

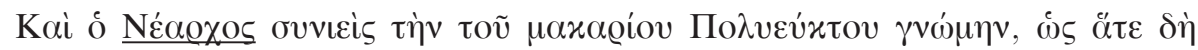

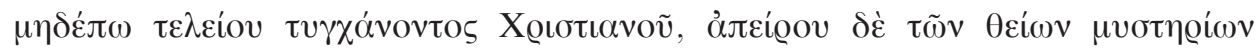

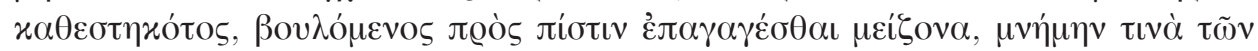

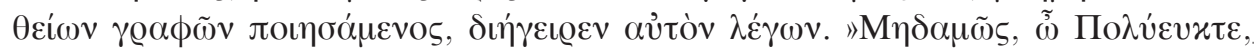

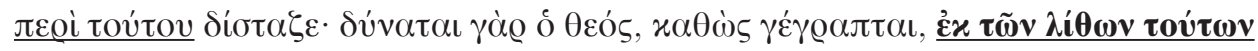

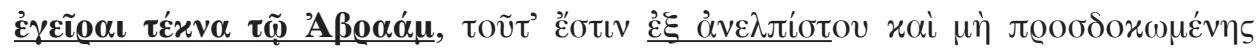

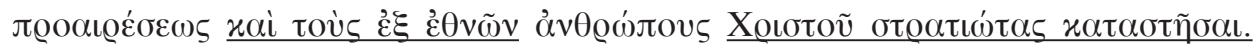

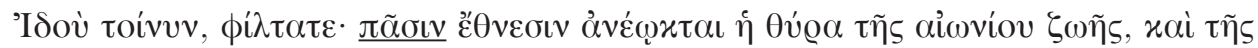

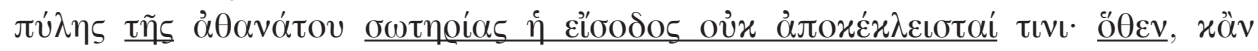

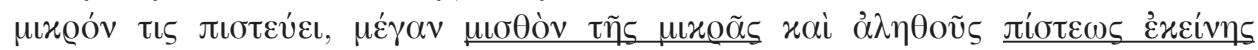

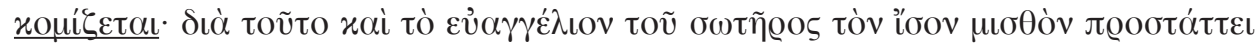

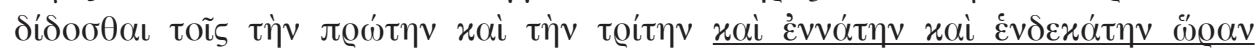

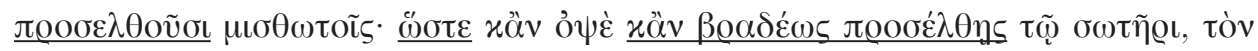

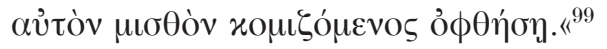

${ }_{97}$ Barlaam-Neuausgabe 28,73-88, großenteils identisch mit $P G$ 96, 1128,15-36.

${ }_{98} P G 114,424$ A 7-B 9.

${ }_{99}$ B. Aubé, Polyeucte dans l'histoire. Étude sur le martyre de Polyeucte d'après des documents inédits. Paris 1882, 91,7-92,10. Die noch unedierte Polyeuktos-Passio $B H G 1567$ d ähnelt in diesem Bereich - mir zugänglich im Cod. Hieros. Sab. 30 (s.X-XI), fol. 255 - dem Cod. Paris. gr. 513, dessen Lesarten Aubé im Apparat beisteuert. 
Vor allem bei der alten Polyeuktos-Passio achte man nicht nur auf die wortwörtliche Übereinstimmung signalisierenden Unterstreichungen, sondern auch ganz allgemein auf den mit dem Barlaam praktisch identischen Kontext. Daß die Suchbegriffe A $\beta 0 \alpha \alpha \mu$ und $\alpha v \varepsilon \lambda \pi \iota \sigma \tau$ sich im TLG nur im Barlaam benachbart fanden, spricht zusätzlich für die Beeinflussung dieses Abschnitts im 28. Barlaam-Kapitel durch die alte Polyeuktos-Passio.

Bei der metaphrastischen Vita des Eremiten Paulus Thebaeus (BHG 1468) handelt es sich um eine klare Metaphrase der sog. griechischen „Vita a" des Paulus (= BHG 1466), und zwar speziell der von den Handschriften $\mathrm{V}^{2} \mathrm{~T}$ gebotenen Form dieser „Vita a“; diese stellt eine nahezu wörtliche Übersetzung von Hieronymus' lateinischer Vita Pauli (BHL 6596) dar. Hieronymus' literarisches Können und sein Erzähltalent sind in ihr erkennbar $^{100}$. Symeon Metaphrastes formte also hier einen durchaus hochwertigen Text um und bediente sich zu diesem Zweck auch ausgiebig des BarlaamRomans. Doch BHG 1466, die Vorlage des Metaphrasten, ist auch schon dem Barlaam-Autor eine Quelle gewesen. Nach Jahren treffen Barlaam und Ioasaph in der Wüste wieder zusammen. Diese Szenerie ist eindeutig von der literarisch nicht minder berühmten Zusammenkunft der greisen Eremiten Paulus und Antonius beeinflußt. Man vergleiche den Kontext und die durch Kursivdruck bzw. Unterstreichung kenntlich gemachten wörtlichen Übereinstimmungen von 1) Barlaam-Roman, 2) metaphrastischer Vita ( $B H G$ 1468) und 3) gemeinsamer Vorlage $B H G 1466$ im Bereich von Barlaams bzw. Paulus' Worten an den jeweiligen Neuankömmling:

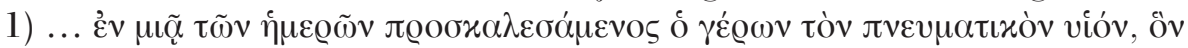

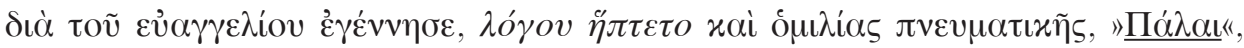

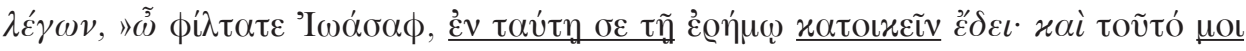

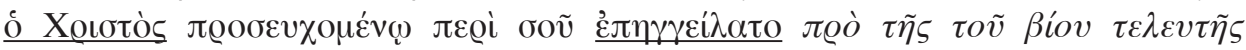

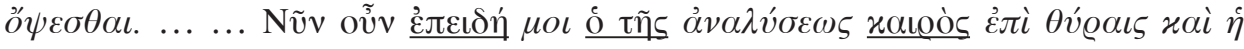

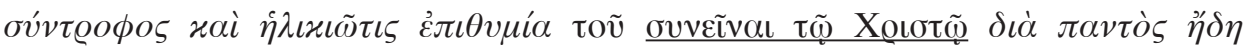

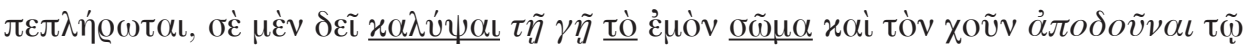

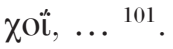

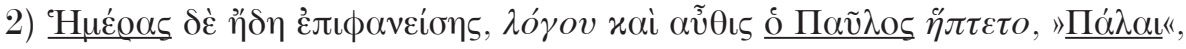

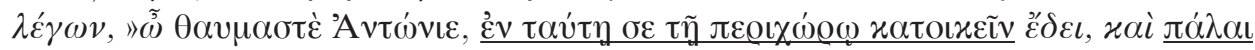

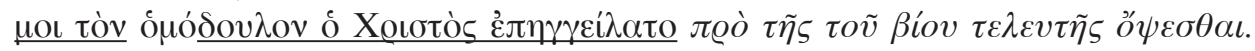

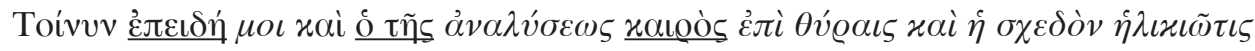

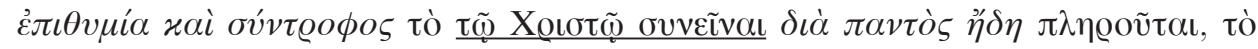

${ }^{100}$ Vgl. K. S. Frank, Paulos v. Theben. $L T h K^{3}, 7$ (1998) 1528-1529.

101 Barlaam-Neuausgabe 39,5-9 und 39,12-15, großenteils identisch mit PG 96, 1224,1117. 


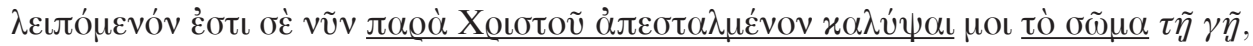

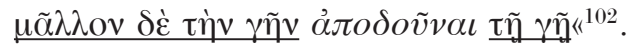

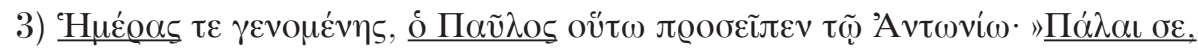

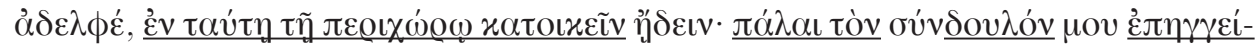

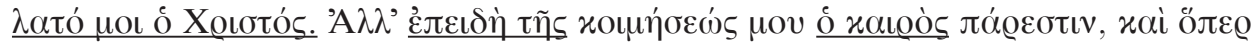

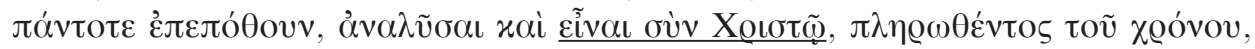

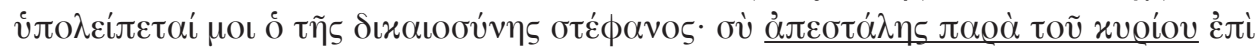

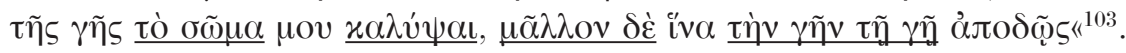

Voraussetzung für den gerade behandelten hieronymianischen Paulustext ist die Vita des Mönchsvaters Antonius aus der Feder des Athanasius von Alexandrien (BHG 140). Mit ihr haben wir einen der von Symeon Metaphrastes unverändert in sein Menologium übernommenen Texte erreicht; er ist schon in der Barlaam-Erstausgabe von Boissonade als Quelle erkannt worden. Quellen für den Barlaam-Autor waren jedoch auch andere alte, in das metaphrastische Menologium inserierte Texte. Ein solcher ist die Passio des Eustratios und seiner Gefährten $(B H G 646)$, ein relativ einfach aufgebauter, aber inhaltlich sehr gehaltvoller Text im vom Metaphrasten ansonsten gern umgearbeiteten Frage- und Antwort-Stil. Ihr entstammt eine ganze Reihe von Wendungen und Gedanken des Barlaam; nur drei Beispiele möchte ich dafür geben:

1) Für den im 2. Barlaam-Kapitel erscheinenden Satz 'Extòs $\delta \dot{\varepsilon} \lambda o ́ \gamma o v$

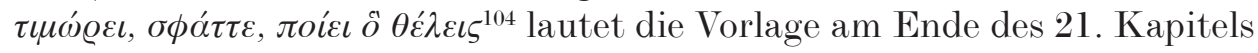

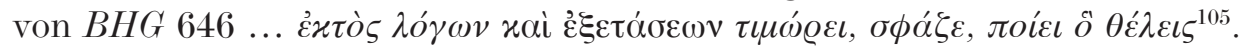

2) Für den etwas weiter unten im 2. Barlaam-Kapitel erscheinenden

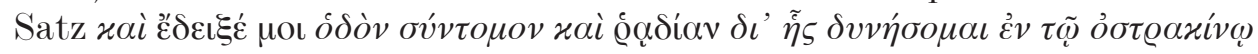

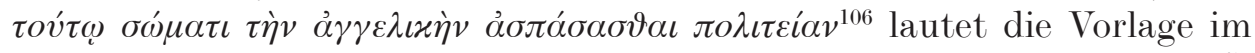

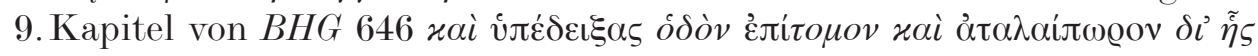

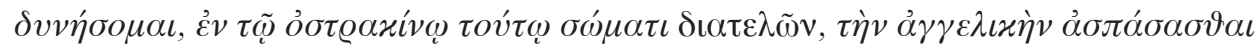
$\pi o \lambda \iota \tau \varepsilon \varepsilon^{\prime} \alpha \nu^{107}$.

102 Symeon Metaphrastes, Passio des Paulus Thebaeus, cap. 14,20-23, ed. K. T. Corey, in: Studies in the text tradition of St. Jerome's Vitae Patrum by J. F. Cherf [u. a.], ed. by W. A. Oldfather with the assistance of M. D. McNeil [u. a.]. Urbana 1943, 217-233, hier 228.

${ }^{103} B H G$ 1466, cap. 11,6-8, ed. K. T. Corey, in: Studies in the text tradition of St. Jerome's Vitae Patrum by J. F. Cherf [u. a.], ed. by W. A. Oldfather with the assistance of M. D. McNeIL [u. a.]. Urbana 1943, 158-172, hier 167.

104 Barlaam-Neuausgabe 2,41-42, identisch mit $P G$ 96, 869,6-7.

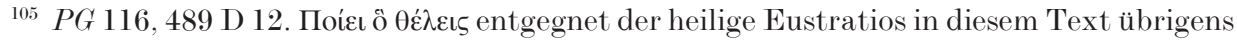
ausgesprochen oft.

106 Barlaam-Neuausgabe 2,93-95, identisch mit $P G$ 96, 872,25-27.

${ }^{107} P G 116,476$ D 8-11. 
3) Die Worte des mit dem heiligen Eustratios über Platon und die Ver-

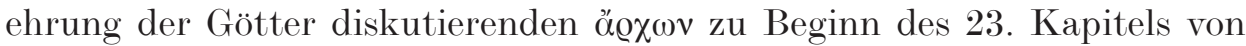

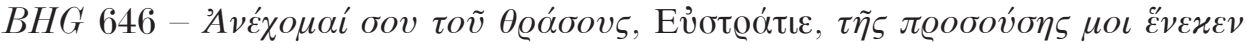
$\phi \iota \lambda \alpha v \theta \varrho \omega \pi i \alpha \varsigma^{108}$ - sind vom Barlaam-Autor offenbar auseinandergerissen und auf eine später auch von Symeon Metaphrastes vielfach praktizierte Weise wie Textbausteine an zwei ähnlichen, jedoch weit auseinander liegenden Stellen (im 2. und im 24. Kapitel) verarbeitet worden. Die Stelle im 2. Barlaam-Kapitel ist unkompliziert, da sich keine gruppenspezifischen

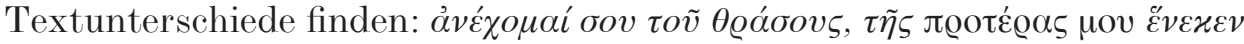

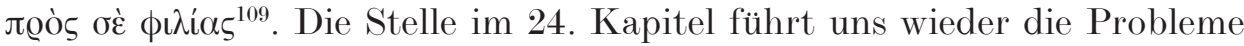
der Barlaam-Überlieferung vor Augen; sie lautet im Lesetext der Neuausgabe, verkörpert durch die Handschriften der urtextnahen Gruppe: $\alpha \lambda \lambda \lambda^{\circ}$

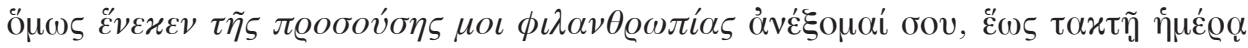

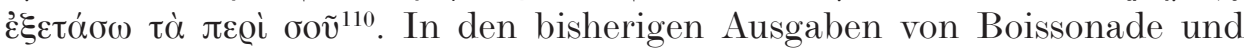
Kechagioglu stimmt sie dagegen völlig mit der Eustratios-Passio überein

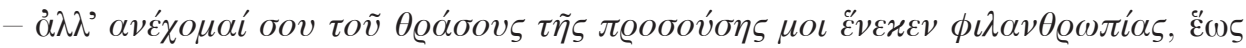

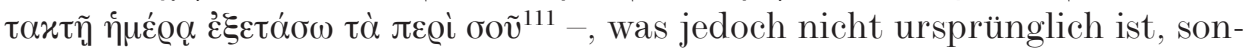
dern, insbesondere was den Zusatz toṽ Ө@óoovs angeht, auf einer Kleingruppe innerhalb der Modifikation A sowie auf der Modifikation D beruht.

Wie schon früher gezeigt, sind im 1. Kapitel der metaphrastischen Vita des heiligen Ioannikios (BHG 937) wesentliche Teile aus dem Prolog des Barlaam-Romans übernommen ${ }^{112}$. Die ins metaphrastische Menologium inserierte alte Vita der Maria Aegyptiaca $(B H G 1042=C P G$ 7675), zugeschrieben dem Sophronios von Jerusalem, macht uns dagegen klar, daß seinerseits der Barlaam-Autor nur ein Zitat gebraucht, wenn er mitteilt, daß er sich der Gefahr bewußt sei, die dem Diener drohe, der das vom Herrn erhaltene Talent unproduktiv in der Erde vergrub, und daß er daher eine bis zu ihm gedrungene erbauliche Geschichte nicht verschweigen werde. Diese Worte in den Anfängen beider Texte sind schlichtweg identisch:

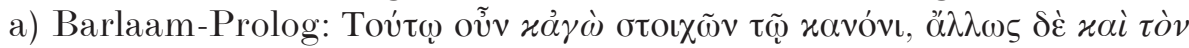

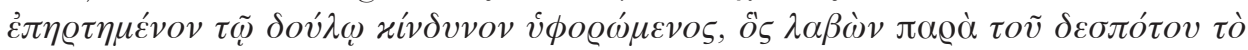

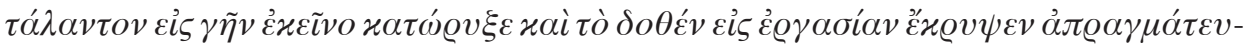

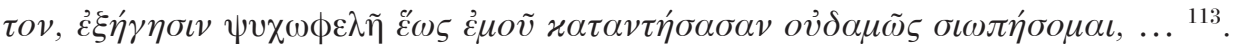

\footnotetext{
${ }^{108} P G 116,492$ D 10-11.

109 Barlaam-Neuausgabe 2,173-174, identisch mit $P G$ 96, 877,3-4.

110 Barlaam-Neuausgabe 24,26-28.

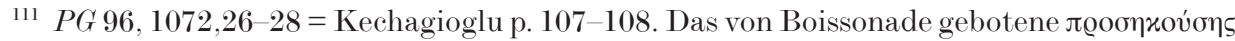
beruht allein auf dem berühmten illuminierten Cod. Paris. gr. 1128, einem Vertreter des älteren Zweigs der Modifikation D.

112 Vgl. Volk (wie Anm. 20) 120-123.

113 Barlaam-Neuausgabe Prol.,26-30, weitgehend identisch mit PG 96, 861,4-10.
} 


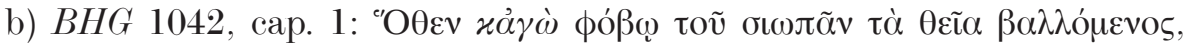

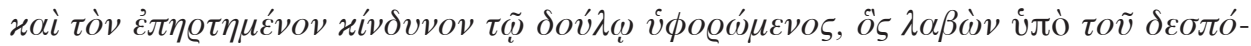

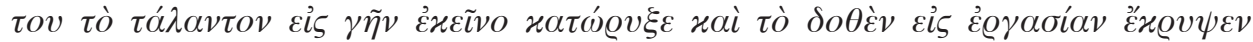

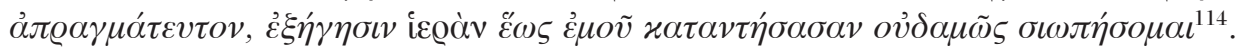

Gesagt werden muß, daß ein längeres Zitat aus BHG 1042 im Florileg zur 3. Bilderrede des Johannes von Damaskus enthalten ist ${ }^{115}$; allerdings ruhen Text und Florileg praktisch auf dem codex unicus $3 \% 6 A^{116}$, dem aus dem 13. Jh. stammenden Neapol. II B 16 (= Sigel D in der Ausgabe). Dieses lange Zitat ist in imag. I $63=$ II 59 ganz kurz zusammengefaßt ('Ev $\tau \tilde{\omega}$

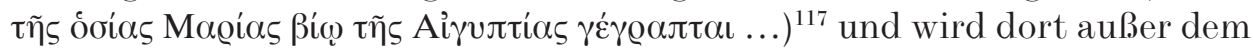
Zeugen D auch noch von den Hss. A (für I 63) und F (II 59) geboten, die auch aus dem 13. Jh. stammen. Für die Barlaam-Frage ist allerdings wichtiger, daß im Anfangskapitel der 2. Bilderrede Johannes von Damaskus ebenfalls davon spricht, seine Predigt deshalb verfaßt zu haben, weil er nicht das Schicksal des Dieners erleiden wolle, der das eine Talent fruchtlos vergraben habe:

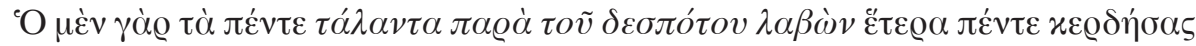

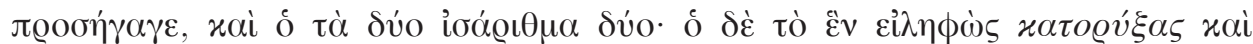

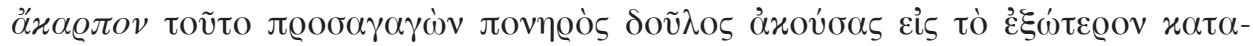

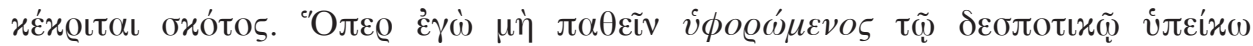

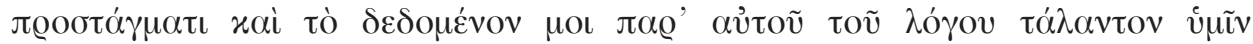

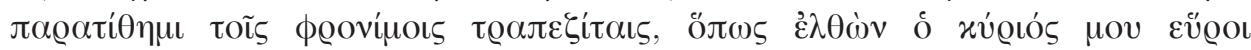

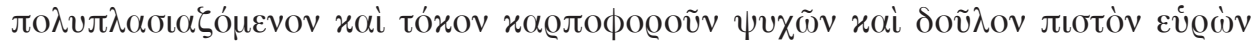

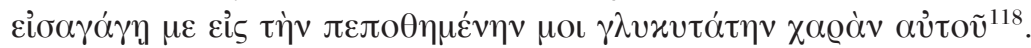

Wahrscheinlich zog er dazu BHG 1042 heran, wie die kursiv gedruckten Schlüsselwörter vermuten lassen. Kotter weist neben Mt 25,14-30 und dem kurzen Vorkommen in Johannes Damascenus' Schrift gegen die Jakobiten

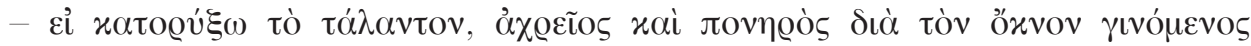

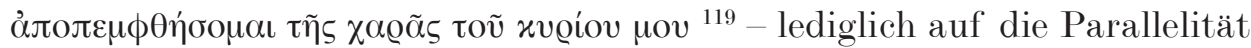

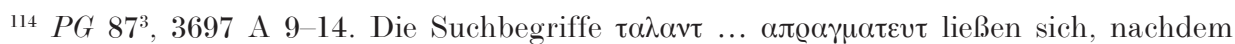
Sophronios v. Jerusalem dort gar nicht eingearbeitet ist, im TLG nur für die BarlaamLegende nachweisen.

${ }^{115}$ Vgl. Die Schriften des Johannes von Damaskos, 3: Contra imaginum calumniatores orationes tres, besorgt von B. KotTER (Patristische Texte und Studien 17). Berlin, New

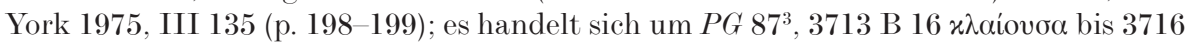

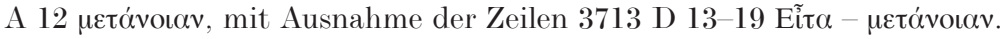

116 Kotter (wie Anm. 115) 25.

117 Vgl. Kotter (wie Anm. 115) 162.

118 KotTer (wie Anm. 115) II 1,11-23 (p. 68-69).

119 Johannes Damascenus, Contra Jacobitas 1,24-26, in: Die Schriften des Johannes von Damaskos, 4: Liber de haeresibus. Opera polemica, besorgt von B. KoTTER (Patristische Texte und Studien 22). Berlin, New York 1981, 110. 
mit dem Barlaam-Roman hin; ebenso wie Dölger war ihm die Zitierung von BHG 1042 im Barlaam-Prolog offenbar völlig unbekannt. Auf alle Fälle ist die Tatsache, daß der Barlaam-Autor in diesem Teil des Prologs keine Eigenständigkeit zeigt, nicht als Argument gegen eine eventuelle Identifizierung dieses Autors mit Johannes von Damaskus geeignet. Neben vielem anderen ist übrigens auch der kurze Barlaam-Epilog von der alten Vita der Maria Aegyptiaca und ihrem viel weitschweifigeren Epilog beeinflußt, $\mathrm{vgl}$.

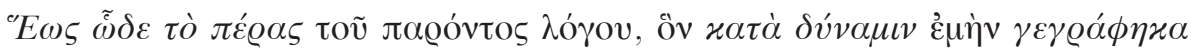

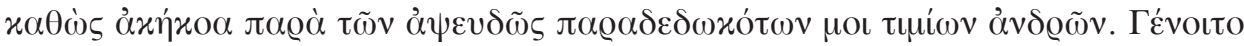

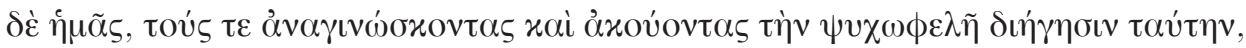

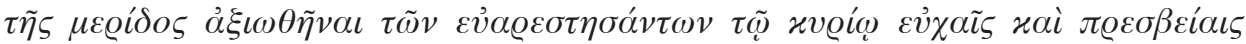

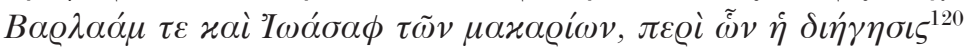

mit

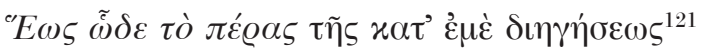

und

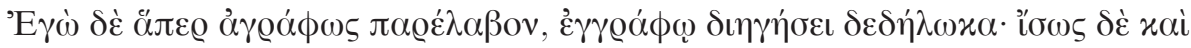

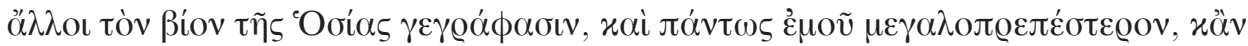

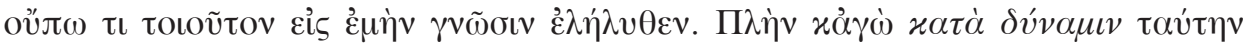

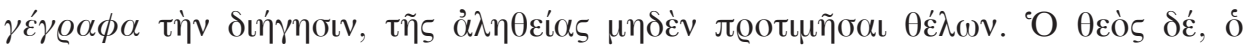

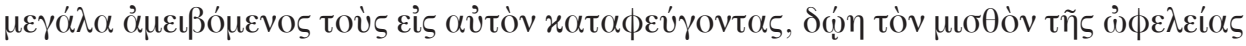

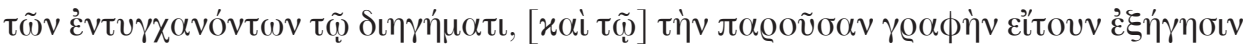

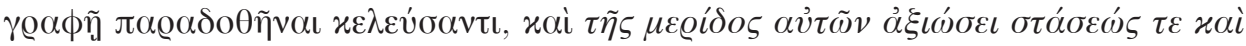

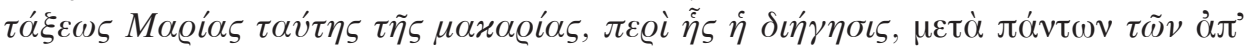

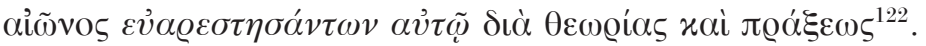

Und sogar die namentliche Vorstellung Barlaams im 6. Kapitel hat ihr Vorbild im 2. Kapitel von $B H G$ 1042, man vergleiche

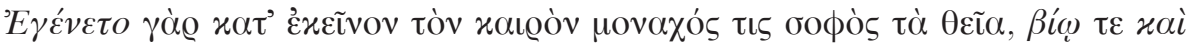

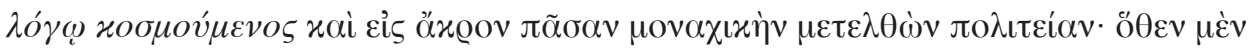

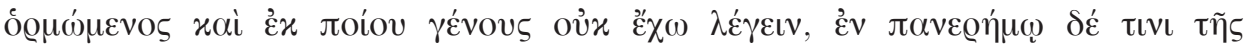

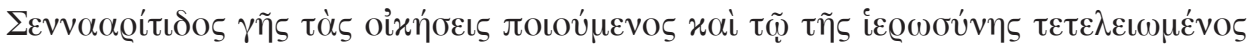

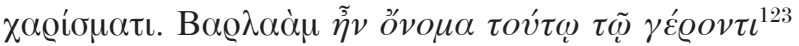

und

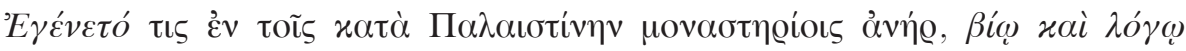

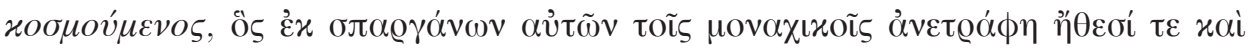

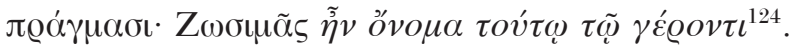

\footnotetext{
${ }^{120}$ Barlaam-Neuausgabe Epil., 1-6, fast völlig identisch mit $P G$ 96, 1240,24-31.

${ }^{121} P G 87^{3}, 3720$ A $5-6$.

${ }^{122} P G 87^{3}, 3725$ B $17-\mathrm{C} 11$.

${ }^{123}$ Barlaam-Neuausgabe 6,1-6, großenteils identisch mit $P G$ 96, 896,23-30.

${ }^{124} P G 87^{3}, 3697$ C 1-3700 A 1.
} 
VII.

$\mathrm{Zu}$ den unsicheren, floskelhaften Barlaam-Parallelen in MetaphrastenTexten der 3. Gruppe kann hier nur ganz kurz etwas gesagt werden. Zu

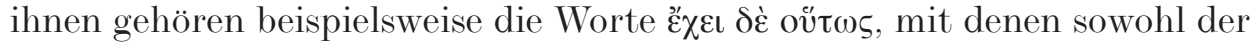
Barlaam-Prolog als auch viele vom Metaphrasten geschaffene Prologe enden (Barl., Prol. 32-33 = PG 96, 861,13-14) ${ }^{125}$. Auffällig ist auch der in dieser Metaphrastentextgruppe häufig erscheinende Hinweis $\phi \theta \alpha \dot{\sigma o s}$ ó

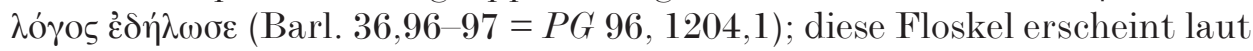
TLG in der Zeit vor Johannes von Damaskus allein bei Euseb, ansonsten massenhaft bei nachdamaszenischen und vor allem nachmetaphrastischen Historikern (Anna Komnene, Nikephoros Bryennios, Georgios Akropolites, Dukas). Ihr vierfaches Vorkommen allein in der Vita des Arsenios (BHG $168)^{126}$ sollte daher bei der Erörterung deren Alters stutzig machen; denn die $B H G$ bezeichnet diesen Normaltext des metaphrastischen Menologiums als inseriert, doch findet sich bei Ehrhard - im Gegensatz zu anderen derartigen Fällen - keinerlei Anhaltspunkt für eine vormetaphrastische Existenz. Neben stilistischen Kriterien macht es die prinzipiell gerne beim Metaphrasten und auch in diesem Text erscheinende, an den Barlaam er-

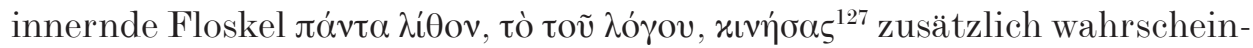
lich, daß es sich bei der Arsenios-Vita BHG 168 um einen echten Metaphrastentext handeln könnte, zumal ja auch wirklich alte Texte über diesen Heiligen $(B H G 167 \mathrm{y}-167 \mathrm{z})$ bekannt sind.

\section{VIII.}

Ein vormetaphrastischer Text etwas unklaren Alters ist schließlich die Vita des gebürtigen Edesseners und Sabasmönches Theodoros, der angeblich in der ersten Hälfte des 9. Jhs. als Bischof von Edessa amtierte und später als Abt von Mar Saba starb (BHG 1744); geschrieben hat sie sein vorgeblicher Neffe und Augenzeuge, ein Bischof Basileios von Emesa. Sie gilt heute als hagiographischer Roman, im späten 9. oder frühen 10. Jh. verfaßt als Apologie des Christentums gegenüber dem Islam und als Pro-

125 Vgl. Volk (wie Anm. 20) 115, Anm. 255 und 123 m. Anm. 287.

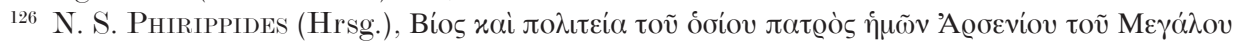

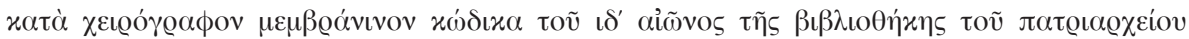

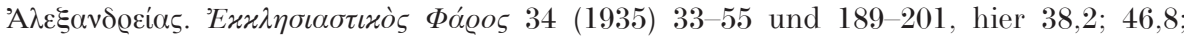
$189,22-190,1$ und 195,20 .

127 Phirippides (wie Anm. 126) 39,22, identisch mit Barlaam-Neuausgabe 2,17 (= PG 96, $868,22-23)$. 
pagandaschrift für Mar Saba ${ }^{128}$. In seinem 1931 erschienenen temperamentvollen und meinungsbildenden Aufsatz über die lateinische Barlaam-Übersetzung von 1048 und die aus ihr zu ziehenden weitreichenden Schlußfolgerungen weist Paul Peeters auf alarmierende Weise auf diesen Text hin ${ }^{129}$ : Das Lemma des Barlaam-Romans, in dem ein Mönch Johannes vom SabasKloster die indische Geschichte nach Jerusalem gebracht hat, sei eine Fälschung; Grundlage sei die im 95. Kapitel von BHG 1744 enthaltene

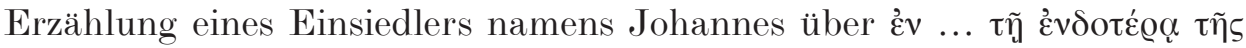

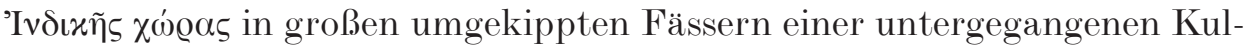
tur lebende christliche Anachoreten ${ }^{130}$. Dieser Mönch - sein Name Johannes erscheint an dieser Stelle nicht, sondern 21 Druckseiten weiter vorne ${ }^{131}$ lebt aber nicht im Sabas-Kloster, sondern erzählt seine Eindrücke von Indien in der Nähe von Bagdad einem kürzlich von Bischof Theodoros von Edessa zum Christentum bekehrten und getauften Kalifen namens $\mathrm{Mu}$ awija (Mavías), der wohl reine Fiktion ist. Ob in BHG 1744 noch irgendwelche anderen mehr oder weniger auffälligen Parallelen mit dem BarlaamRoman, den er für jünger als die Theodoros-Vita hält, existieren, teilt Peeters nicht mit. Zudem ist heute seine mit keinerlei Textvergleich untermauerte Ansicht absolut unhaltbar, daß es kein einziges Indiz gebe, um den Barlaam-Roman in die Zeit vor Symeon Metaphrastes zu datieren ${ }^{132}$. Und inzwischen gibt es noch eine weitere Theorie zu eventuellen Verbindungen zwischen $B H G 1744$ und dem Barlaam. Falls nämlich die Vermutung richtig wäre, daß die Produktion griechischer Texte in den orientalischen Patriarchaten im 9. Jh. selten wird oder gar zum Erliegen kommt, so stellte Sidney H. Griffith 1986 in ganz anderem Zusammenhang fest, dann bedürfen drei Werke aus diesem Raum und Zeitpunkt besonderer Aufmerksamkeit $^{133}$. Es handelt sich bei ihnen 1) um den Brief der drei orientalischen Patriarchen an Kaiser Theophilos, angeblich 836 auf einer Synode zu Jerusalem verfaßt, 2) um die Vita des Theodoros von Edessa (BHG 1744) und

${ }^{128}$ Vgl. U. ZanetTi, Theodoros, hl., Bf. v. Edessa. LThK ${ }^{3}, 9$ (2000) 1410-1411 und A. KazhDAN, Theodore of Edessa. ODB, 3 (1991) 2043.

129 P. Peeters, La première traduction latine de „Barlaam et Joasaph“ et son original grec. AnBoll 49 (1931) 276-312, hier 296-298.

${ }^{130} \mathrm{Vgl}$. Peeters (wie Anm. 129) 296-297, BHG 1744 zitierend nach I. Ponjalovski.J (Hrsg.), Žitie iže vo svjatych otca našego Feodora archiepiskopa Edesskago. St.-Petersburg 1892, 101,21-102,3.

131 Vgl. Ponjalovskij (wie Anm. 130) 80,5.

132 Vgl. Peeters (wie Anm. 129) 307.

133 Vgl. S. H. Griffith, Greek into Arabic: Life and letters in the monasteries of Palestine in the ninth century; the example of the Summa Theologiae Arabica. Byz 56 (1986) $117-138$, hier 131 . 
3) um den Barlaam-Roman, den Griffith aufgrund der damals noch ganz neuen, noch ungedruckt privat in Washington, D.C. zirkulierenden Theorie Kazhdans als Werk des 9. Jhs. ansieht ${ }^{134}$. Alle diese drei Werke könnten und nach Griffith sei dies the most commendable hypothesis ${ }^{135}$ - in Konstantinopel und gar nicht im Orient entstanden sein, vielleicht unter aktiver Mithilfe von dort lebenden, aus Palästina geflohenen Mönchen ${ }^{136}$. Der Brief der drei orientalischen Patriarchen wurde seither zweimal neu ediert ${ }^{137}$, und Griffiths Hypothese wird darin überhaupt nicht angesprochen; irgendwelche Parallelen mit der Barlaam-Legende weist er im übrigen nicht auf. Umso mehr Grund lag also vor, auch die Theodoros-Vita BHG 1744 nach Barlaam-Parallelen zu untersuchen, und es fanden sich viele kleine und einige ziemlich umfangreiche, von denen man sich die wohl interessanteste

134 Vgl. Griffith (wie Anm. 133) 131 m. Anm. 47. - Diese Theorie ist heute wohlbekannt, vgl. A. Kazhdan, Where, when and by whom was the Greek Barlaam and Ioasaph not written. Zu Alexander d. Gr. Festschrift G. Wirth zum 60. Geburtstag am 9. 12. 1986. Amsterdam 1988, 1187-1209, nachgedruckt in Ders., Authors and texts in Byzantium (Variorum Collected Studies 400). Aldershot 1993, Teil IX. Ohne eigene Hss.-Kollation geht sie von einem einheitlichen Barlaam-Text aus und ist sowohl gegen Johannes von Damaskus als auch gegen Euthymios gerichtet; der Autor müsse vielmehr zeitlich zwischen diesen beiden Polen gesucht werden. The Greek Barlaam, most probably, belonged to the corpus of Sabaite apologetic literature of around 800 (a.a.O. 1207). Der mit großem Vorbehalt (only shadowy hypothesis, a.a.O. 1206) genannte mögliche Autor-Kandidat - an einem Sabas-Mönch Johannes führte für Kazhdan damals kein Weg vorbei - ist der in der Vita des Stephanos Sabaïtes (BHG 1670) erscheinende Johannes, der im

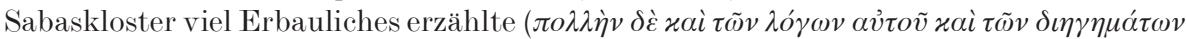

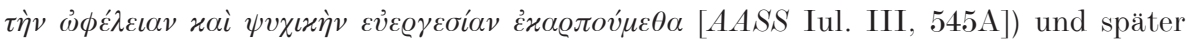
Bischof von Charachmoba wurde.

135 Griffith (wie Anm. 133) 131.

136 Vgl. Griffith (wie Anm. 133) 131-133. - Diesen Gedanken hat Kazhdan in seinem posthum erschienenen Spätwerk A history of Byzantine literature (wie Anm. 26) $99 \mathrm{~m}$. Anm. 14 aufgegriffen, kommt aber insgesamt zu dem Schluß, daß wir von einer Lösung der Autorfrage des Barlaam noch weit entfernt sind: If we assume that the author of the Barlaam was not Damaskenos, but another member of the community of St. Sabas, when could the work have been compiled? Theophanes says that the famous lavrae of St. Chariton and of St. Sabas were deserted by either 809 or 813 . If we take this statement at face value, John Sabaite must have written before this date. But can we be sure that the great work was created in Mar-Saba or in Jerusalem and not in Constantinople, in the milieu of Palestinian émigrés, as may well have been the case with the Vita of Theodore of Edessa? To sum up, we should stress that the complex issue of the authorship of the Barlaam is still far from solved.

${ }^{137}$ H. Gauer, Texte zum byzantinischen Bilderstreit. Der Synodalbrief der drei Patriarchen des Ostens von 836 und seine Verwandlung in sieben Jahrhunderten (Studien und Texte zur Byzantinistik 1). Frankfurt am Main [u. a.] 1994 und J. A. Munitiz [u. a.] (Hrsg.), The letter of the three patriarchs to emperor Theophilos and related texts. Camberley/Surrey 1997. 
unbedingt vor Augen führen sollte. Sie erscheint im 42. Kapitel von $B H G$ 1744, wo Theodoros als zum Bischof von Edessa ernannter Mönch des Sabas-Klosters Abschied von seinen Mitbrüdern nimmt:

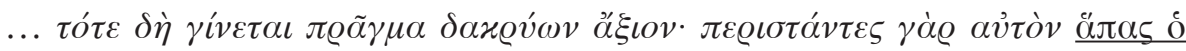

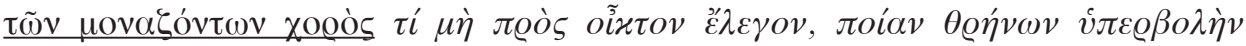

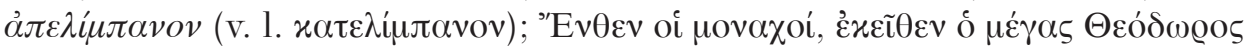

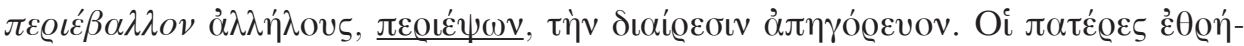

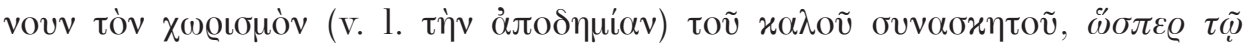

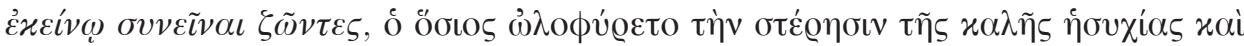

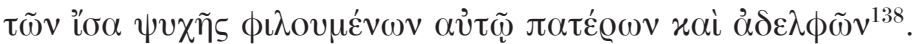

Die Übereinstimmungen mit dem 36. Barlaam-Kapitel, in dem am Ende König Ioasaph Abschied von seinem Volk nimmt, um als Einsiedler in die Wüste zu gehen, sind frappierend, und es empfiehlt sich, hier gleich die ganze Abschiedsszene abzudrucken, da wir sie bald nochmals benötigen:

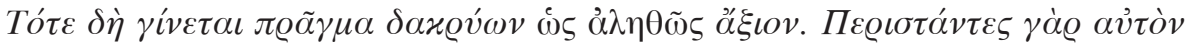

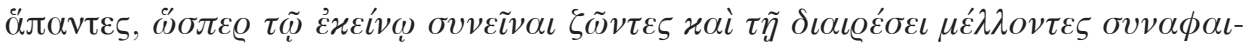

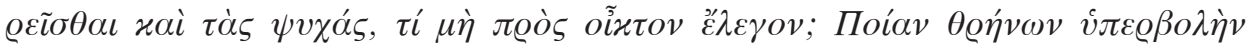

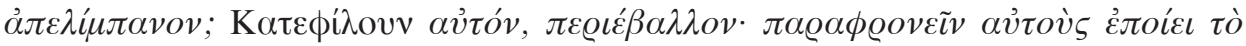

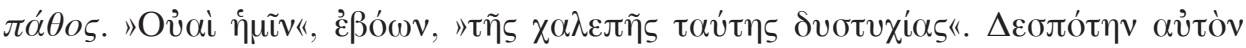

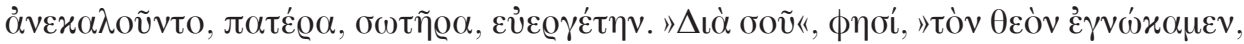

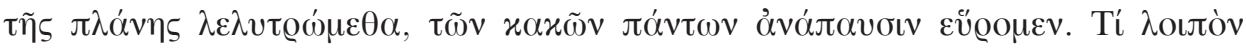

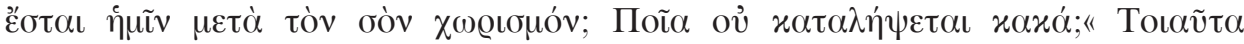

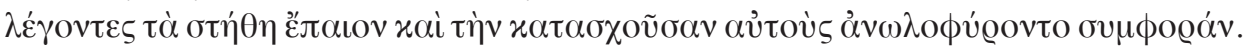

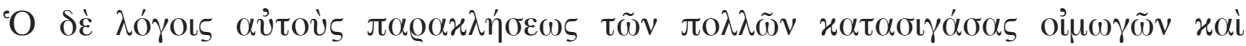

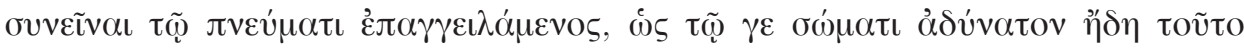

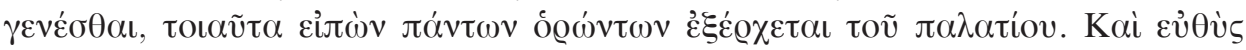

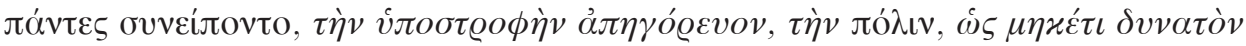

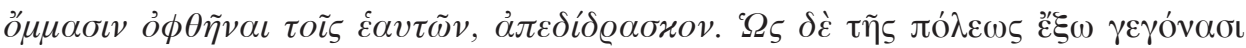

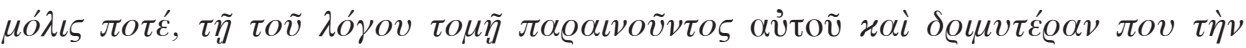

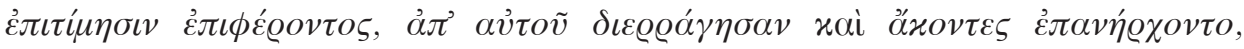

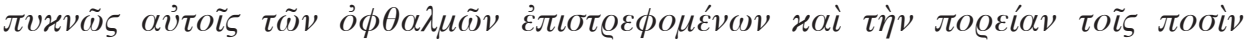

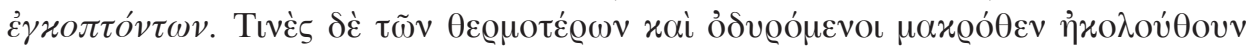

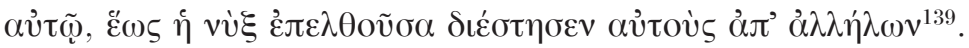

Welcher Text aber ist älter? Dies läßt sich aus diesen Parallelen strenggenommen noch nicht ersehen, in denen zudem der ursprüngliche Barlaamtext und seine Modifikationen A bis D praktisch identisch sind. Immerhin

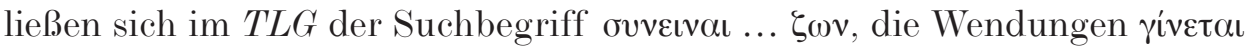

138 Ponjalovskij (wie Anm. 130) 38,22-29.

139 Barlaam-Neuausgabe 36,185-208, identisch mit $P G$ 96, 1208,21-1209,11. 


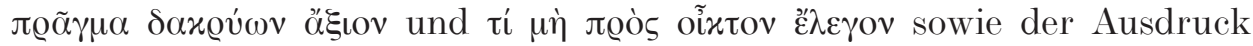

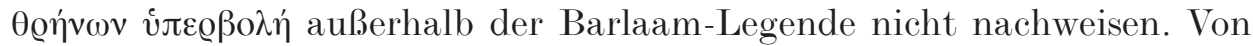
Interesse ist daher sicher die Beobachtung, daß die Szene im 11. Kapitel der metaphrastischen Johannes-Chrysostomos-Vita (BHG 875), in der der Heilige im Zusammenhang mit seiner Priesterweihe durch Bischof Flavianos Abschied von seinem Kloster bei Antiocheia nimmt, den Eindruck erweckt, als sei sie aus der Barlaamstelle (kursiv) und BHG 1744 (unterstrichen) zusammenkomponiert, wobei die Heranziehung des BarlaamRomans schon umfangmäßig dominiert:

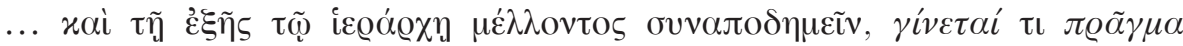

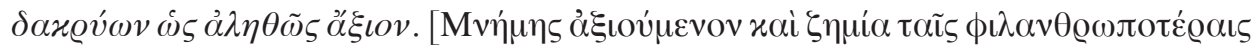

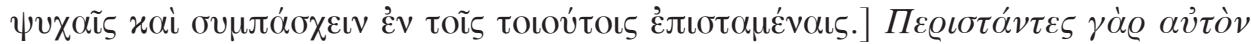

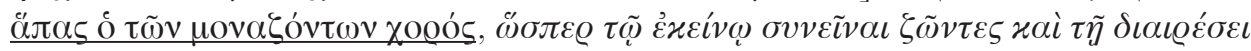

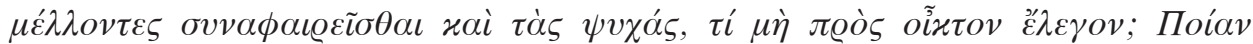

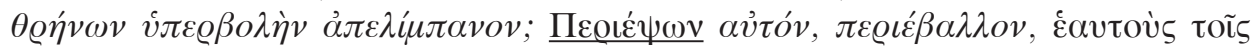

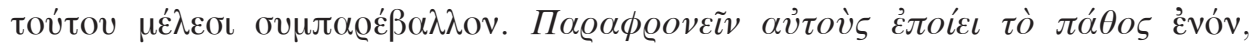

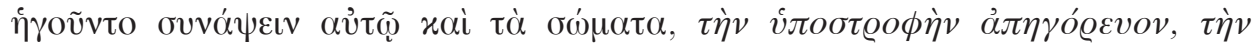

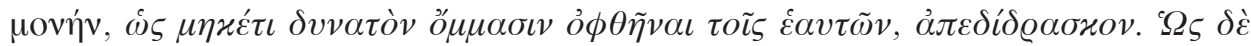

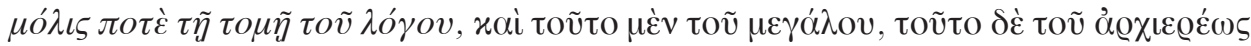

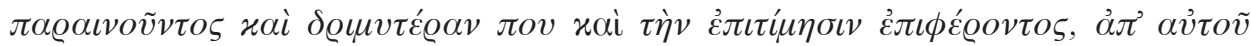

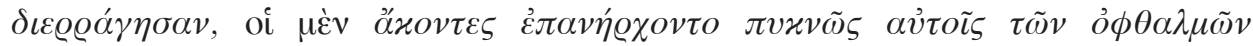

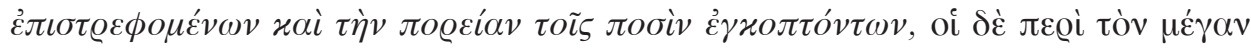

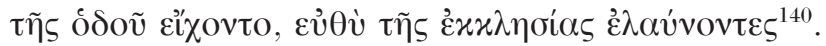

Die von Symeon Metaphrastes stets benutzte Barlaam-Modifikation B

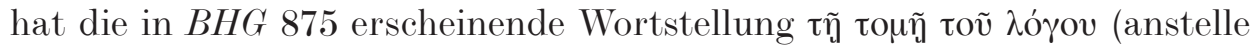

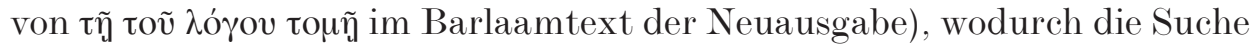
nach einer Vorlage des Metaphrastentextes BHG 875, die auch den Barlaam beeinflußt haben könnte, schon fast überflüssig erscheint. Tatsächlich tun wir uns mit der Vorlagenbestimmung etwas schwer. Die bisher offenbar nur

${ }^{140}$ PG 114, 1073 C 10-1076 A 2. Die das mutmaßliche Barlaam-Zitat unterbrechenden, eckig eingeklammerten Worte finden sich derart bereits in der bei Migne nur nachgedruckten Ausgabe von H. Savilius (Hrsg.), S. Ioannis Chrysostomi opera graece, 8. Eton 1612, 383,20-22; Angaben dazu macht Savilius weder auf dieser Seite noch in seinen Notae in tomum octavum. Seine Textgrundlage sind zwei unzureichend beschriebene Pariser Hss.; nur eine von ihnen wird diese eingeklammerte nichtursprüngliche, nicht aus dem Barlaam geflossene Ergänzung enthalten. Sie findet sich auch nicht in der bei Migne parallel abgedruckten lateinischen Übersetzung von Surius, deren zugrundeliegende griechische Hs. im übrigen ganz unbekannt ist, vgl. EHRHARD, Überlieferung und

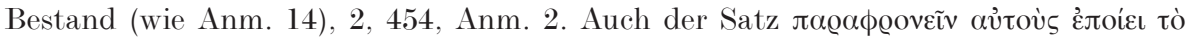

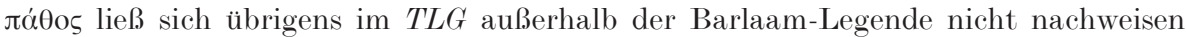
(Suchbegriffe $\pi \alpha \varrho \alpha \phi \varrho o v \varepsilon ı$... $\pi \alpha \theta \circ \varsigma$ ). 
maschinenschriftlich vollständig edierte älteste Chrysostomos-Vita des Pseudo-Martyrius von Antiocheia $(B H G 871=C P G 6517)^{141}$ wird heute mit überzeugenden Argumenten als ein schon sehr bald nach dem Tod des Heiligen entstandenes Dokument des 5. Jhs. angesehen ${ }^{142}$. Ihre beiden mir zugänglichen Teileditionen ${ }^{143}$ berühren die Priesterweihe des Johannes Chrysostomos nicht. Sichere Quellen des Symeon Metaphrastes sind die lange Chrysostomus-Vita des Georgios von Alexandrien (BHG $873=C P G$ 7979) und die anonyme Chrysostomus-Vita $B H G$ 876 $6^{144}$; sie handeln ausgiebig von der Priesterweihe des Heiligen und dem Weggang von seinem Kloster, der Barlaam-Autor kann aus ihnen jedoch so gut wie überhaupt nichts wörtlich für seine Abschiedsszene entnommen haben. Man betrachte zunächst die Vita des Georgios von Alexandrien $(B H G 873=C P G 7979)^{145}$ :

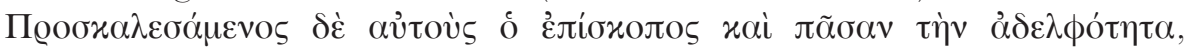

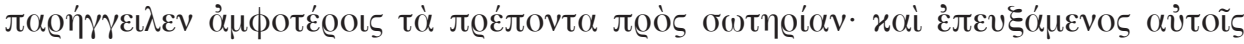

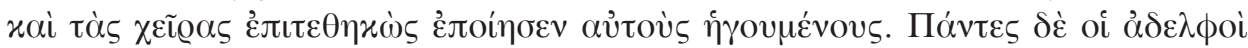

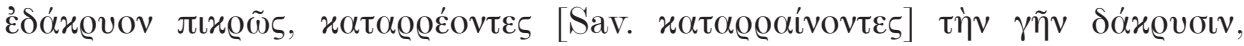

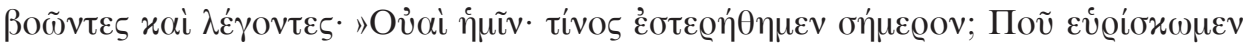

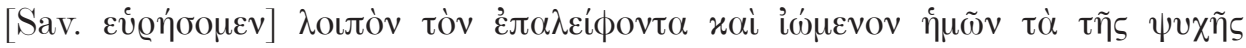

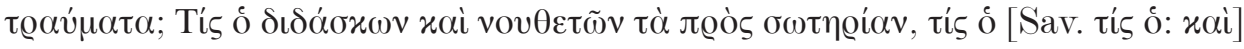

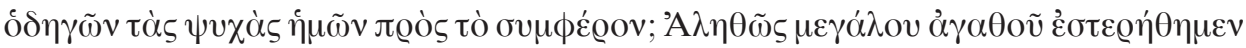

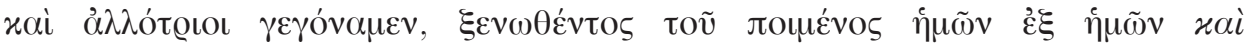

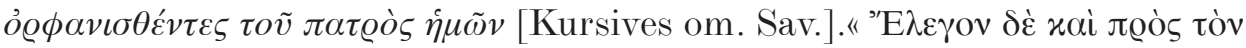

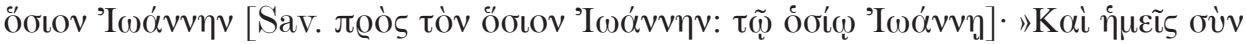

${ }^{141}$ F. van Ommeslaeghe, De lijkrede voor Johannes Chrysostomus [thes. dactyl.]. Leuven 1974; sie war mir bisher unzugänglich.

${ }^{142}$ Vgl. F. van Ommeslaeghe, Le valeur historique de la Vie de S. Jean Chrysostome attribuée à Martyrius d'Antioche (BHG 871), in: Studia Patristica XII. Papers presented to the Sixth International Conference on Patristic Studies held in Oxford 1971, part 1 (TU 115). Berlin 1975, 478-483.

${ }^{143}$ L. A. Mingarelli, Graeci codices manu scripti apud Nanios patricios Venetos asservati. Bologna 1784, 337-338 und A. MaI, Nova Patrum Bibliotheca, 2. Rom 1844, 546-551 $=P G 47$, XLIII-LII.

${ }^{144}$ Vgl. a. Chr. Bavr, Der heilige Johannes Chrysostomus und seine Zeit, 1. München 1929, XXI-XXII.

${ }^{145}$ Erstausgabe: Savilius (wie Anm. 140) 8, 157-265 nach den Codd. Vat. Palat. gr. 80

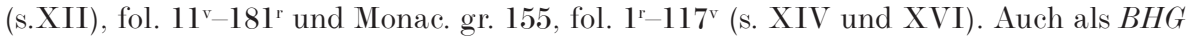
873bd bezeichnete Neuausgabe: F. Halkin (Hrsg.), Douze récits sur saint Jean Chrysostome (Subsidia hagiographica 60). Brüssel 1977, 69-285 nach den Codd. Vind. hist. gr. 5 (ca. a. 1000), fol. 135 $-235^{\mathrm{r}}$ und Athous Iber. 263 (s. XV), fol. $373^{\mathrm{v}}-466^{\mathrm{v}}$. Halkin folgt in der Kapitelzählung der SaviLIus-Ausgabe, gibt aber leider die von dieser gebotenen Lesarten nicht in seinem Apparat wieder; ich habe sie für den hier abgedruckten Abschnitt des 16. Kapitels vermerkt. 


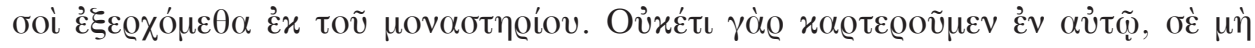

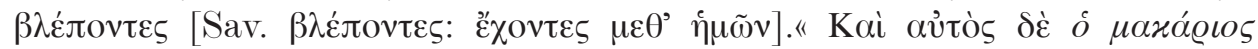

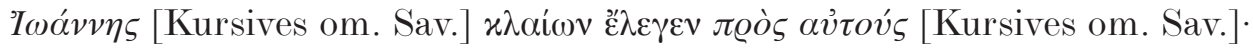

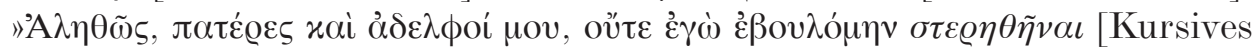

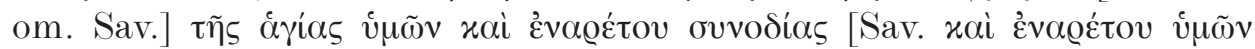

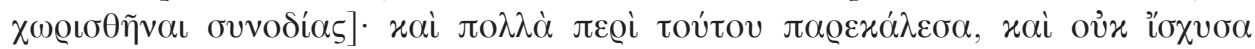

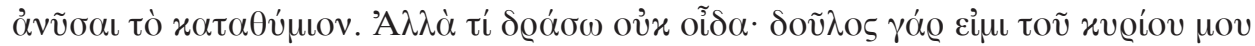

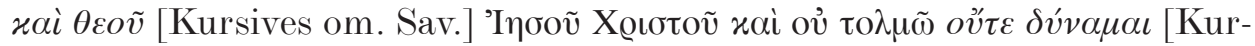

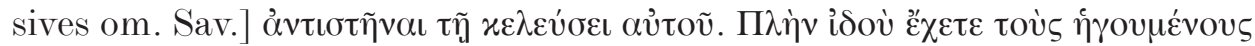

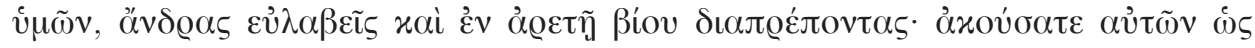

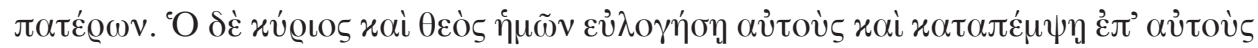

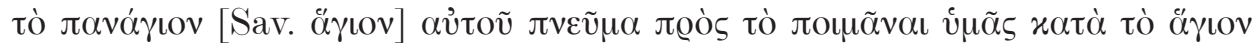

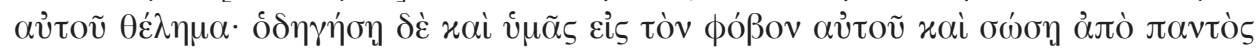

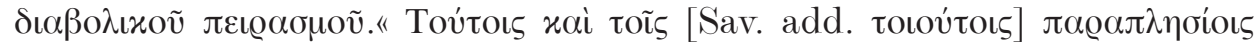

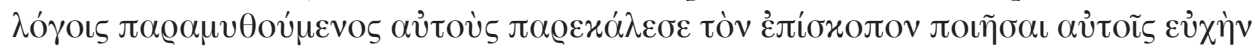

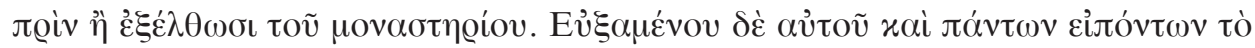

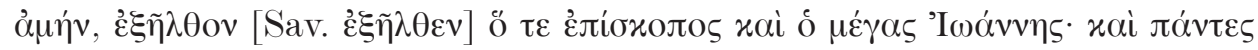

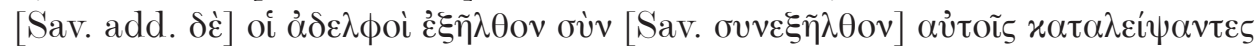

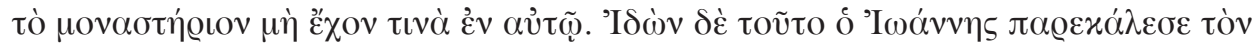

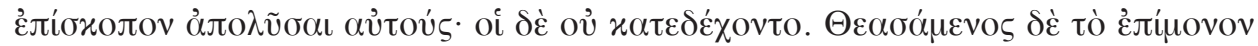

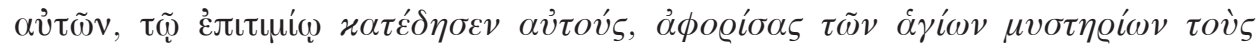

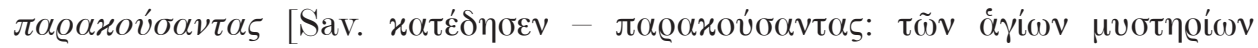

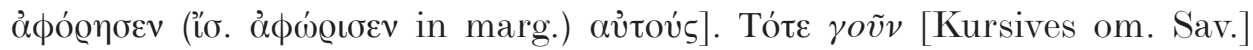

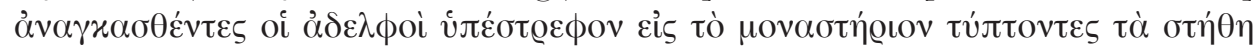

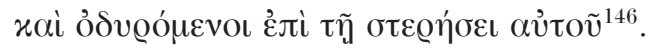

Auch die im gleichen Zusammenhang stehende Abschiedsszene im 20. Kapitel der wohl aus der Mitte des 10. Jhs. stammenden, relativ selten überlieferten anonymen Vita $B H G \quad 876^{147}$ zeigt in ihrer Wortwahl keine Gemeinsamkeiten mit dem Metaphrastentext und stimmt auch mit der Barlaam-Legende nicht überein:

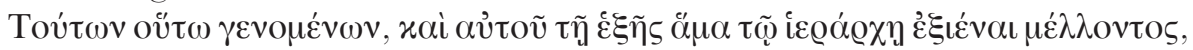

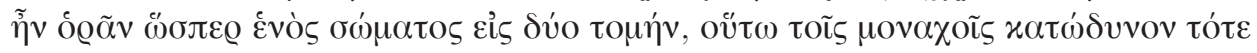

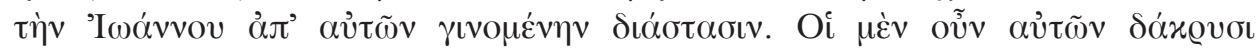

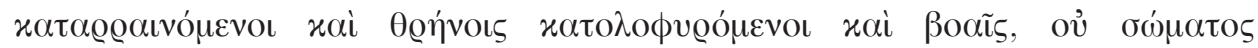

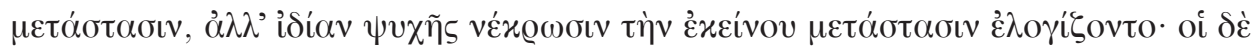

146 Savilius (wie Anm. 140) 8, 177,44-178,24 = Halkin, Douze récits (wie Anm. 145) $111,30-113,2$.

147 Ediert bisher nur bei Savilius (wie Anm. 140) 8, 294-371 nach Cod. Vindob. hist. gr. 52 (a.1557), fol. $1^{\mathrm{v}}-78^{\mathrm{r}}$, der eine Abschrift des heutigen Cod. Monac. gr. 108, fol. 7-82 (s.XI) ist. 


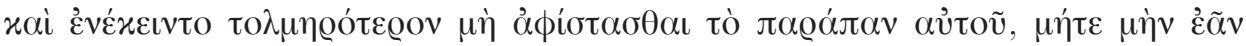

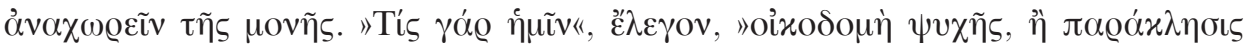

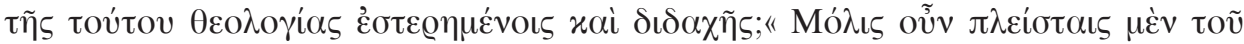

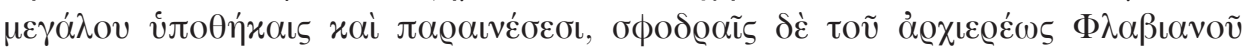

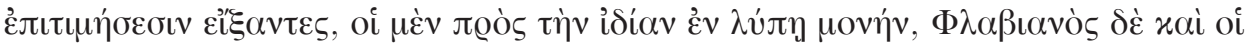

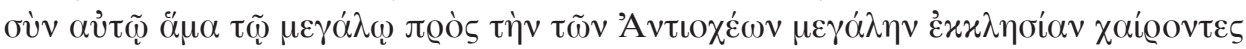
ทैं $\sigma \alpha v^{148}$.

\section{IX.}

Hier will ich nun zum Schluß kommen. Nachdem sicher feststehen dürfte, daß Symeon Metaphrastes bzw. sein Team sich stets desselben Zeugen der eher zweitrangigen Barlaam-Modifikation B zur Verarbeitung in den Metaphrasen bediente, stellen sich einige alte Fragen neu und überhaupt einige ganz neue Fragen. Wie hat man sich die Redaktionsarbeit des metaphrastischen Teams, über das uns Michael Psellos einiges verrät ${ }^{149}$, vorzustellen? Handelte es sich um Bewunderer der Barlaam-Legende mit einem großen Zettelkasten? Deren 30. Kapitel beispielsweise wird regelrecht zerschnitten und seine verschiedenen Zeilen auf ganz verschiedene Metaphrastentexte verteilt. Gab es einen ganzen Kanon von Quellentexten, die das metaphrastische Team verwertete, und war der Barlaam nur ein Text davon? Man denke nur an die gemeinsamen Quellentexte der Barlaam-Legende und Symeons Metaphrasen; ein solcher ist beispielsweise auch die im Barlaam nur kurz herangezogene, in der metaphrastischen Passio des Bischofs Babylas (BHG 206) dagegen ausgiebig und wortwörtlich verarbeitete Johannes-Chrysostomos-Schrift Ad Stagirium a daemone vexatum $(C P G 4310)^{150}$. Bei der Beantwortung solcher Fragen stehen wir erst am Anfang. Wird erst einmal die gesamte byzantinische Literatur oder wenigstens die gesamte Patrologia Graeca auf künftigen CD-ROMs des TLG

148 Savilius (wie Anm. 140) 8, 308,31-41.

149 Vgl. C. Høges, The redaction of Symeon Metaphrastes. Literary aspects of the Metaphrastic martyria, in: Metaphrasis. Redactions and audiences in Middle Byzantine hagiography, ed. by C. HøgeL (KULTs skriftserie 59). Oslo 1996, 7-21, hier 7-11.

150 Johannes Chrysostomus, Ad Stagirium a daemone vexatum I 2 (PG 47, 427,46-428,23) und Symeon Metaphrastes, Passio s. Babylae c. 4 (PG 114, 972 A 8 - B 11) entsprechen sich größtenteils wortwörtlich, während nur wenige Zeilen des 2. Barlaam-Kapitels

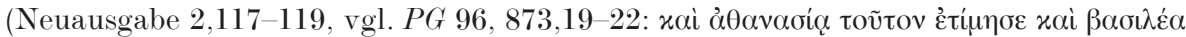

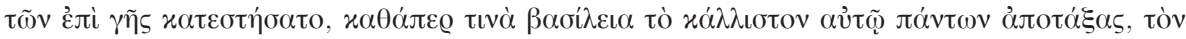
$\pi \alpha \varrho \alpha ́ \delta \varepsilon เ \sigma o v)$ von diesem Chrysostomos-Text $(P G 47,428,3-5)$ beeinflußt sind (Пoı́ $\sigma \alpha \varsigma$

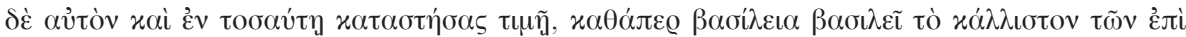

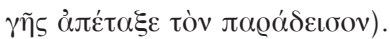


enthalten sein, so dürften sich viele Probleme wesentlich leichter lösen lassen. Aufmerksamkeit und vor allem Zeit werden aber noch immer notwendig sein, auch wenn dieser Idealzustand erreicht wäre, von dem frühere Forschergenerationen nur träumen konnten. Vorläufig läßt sich sagen: Der Autor der griechischen Barlaam-Legende zitiert ausgiebig aus der älteren, vielleicht auch aus der zeitgenössischen, beileibe nicht nur hagiographischen Literatur, und er wird - selbst souverän mit der Sprache umgehend - von beileibe nicht nur hagiographischen Autoren nach ihm ausgiebig zitiert. 
